\title{
الاحتياجات التدريبية لأعضاء هيئة التدريس بجامعة تبوك في ضوء متطلبات جودة التعليم الجامعي
}

\author{
محمد بن عوض الأسمري \\ أستاذ مساعد في إدارة وتخطيط برامج التعليم المستمر - جامعة تبوك- المملكة العبية السعودية
}

Malasmrai@ut.edu.sa

هدفت الدراسة إلى تحديد الاحتياجات التدريبية لدى أعضاء الهيئة التدريسية في جامعة تبوك في ضوء متطلبات جودة التعليم الجامعي وشملت عينة الدراسة لVV عضواً من أعضاء هيئة التدريس بجامعة تبوك، وتضمنت الاستبانة الحاجات التدريبية المتعلقة بالمهارات الآتية:

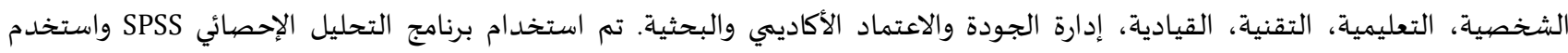

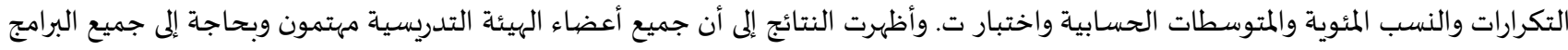

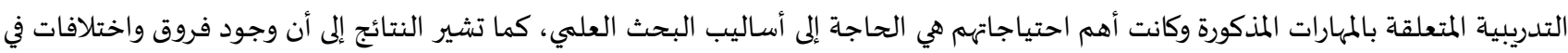

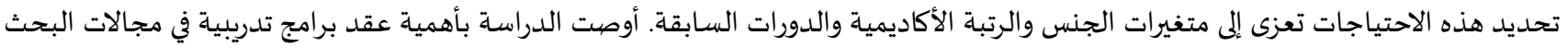

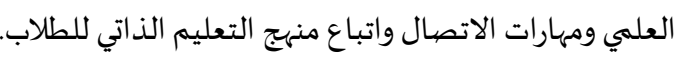

الكلمات المفتاحية: الاحتياجات التدريبية؛ جامعة تبوك؛ أعضاء الهيئة التدريسية. (ㅇ) (b)

تُعتبر الجامعات إحدى أهم مؤسسات التعليم العالي التي تساهم بشكل كبير في صنع العناصر القيادية في المجتمع سواء أكان على الصعيد المهني

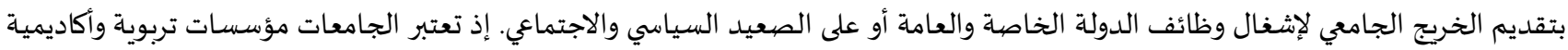
وتعليمية في أن واحد مما يجعلها تتسم بخصائص مميزة في أهدافها وأنشطتها وبالتالي علاقتها معقدة مع المؤسئسيات التهات التعليمية وجميع المؤسسات الأخرى. فنظرا إلى التطور الهائل والسريع في تكنولوجيا المعلومات كان لزاما على مؤسسات التعليم العالي من التكيف والتطور واستيعاب هذا التطور لترتقي إلى المي المستوى المرجو مناه. ونظراً لهذه التغيرات المتسارعة يواجه قطاع التعليم في الجامعات العديد من التحديات مثل: التطور الهائل بوسائل التكنولوجيا، اقتصار دور

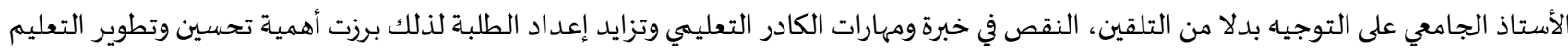

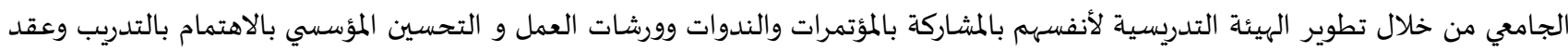
المؤتمرات ودعم البحث العلمي (Abouelenein and Yousri, 2016).

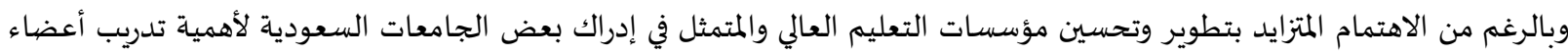

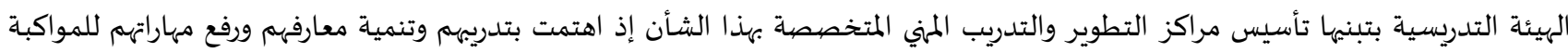

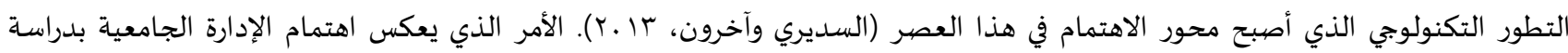

الاحتياجات التدريبية لدى الهيئة التدريسية.

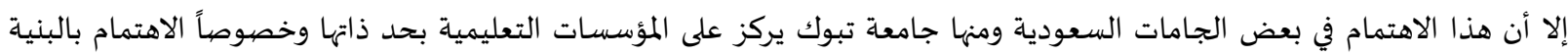

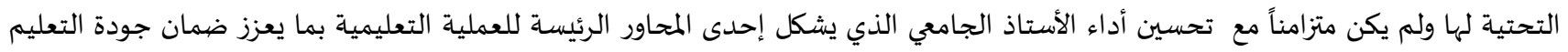


الجامعي، وهذا أحد الأسباب الرئيسة لعدم ضمان فاعلية أداء عضو هيئة التدريس في البيئة التعليمية، وعدم الاهتمام بشكل كافٍ في إعداده وتطويره

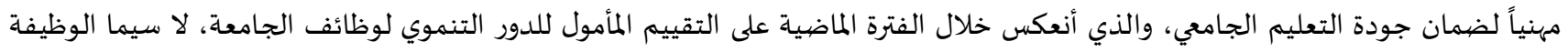
التعليمية التي لم يصل مستواها إلى الحد الأدنى المطلوب، إلا من خلال التدريب أثناء الخدمة الأستاذ الجامعي كوسيلة لتطوير البيئة التعليمياة في

الجامعة.

مشكلة الدراسـة:

تتحدد مشكلة الدراسة في الأسئلة الآتياة: ما الاحتياجات التدرببية لأعضياء هيئة التدريس بجامعة تبوك في مجالات (التعليمية- البحثية- التقنية- الجودة والاعتماد الأكاديمي- القياديةتطوير الذات) في ضوء متطلبات جودة التعليم الجامعي من وجهات نظرهم؟ هل توجد فروق ذات دلالة إحصائية بين متوسطات استجابات أعضياء هيئة التدريس حول تقديرهم لمدى احتياجاتهم التدريبية في ضوء الاحتياجات التدريبية، والتي تعزى إلى اختلاف متغيرات (الكلية، سنوات دوات الخبرة، العمر، الدورات متوسات التدريبية)؟

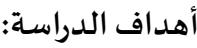

هدفت الدراسة الحالية إلى التعرف على: الاحتياجات التدريبية لأعضاء هيئة التدريس بجامعة تبوك في المجالات التالية (التعليمية- البحثية- التقنية- الجودة والاعتماد الأكاديمي-

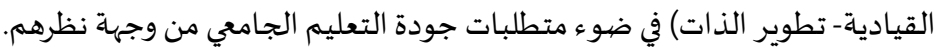
مدى وجود فروق ذات دلالة إحصائية بين متوسطات استجابات أعضاء هيئة التدريس حول تقديرهم لمدى احتياجاتهم التدريبية في ضوء متطلبات جودة التعليم الجامعي، والتي تعزى إلى اختلاف متغيرات (الكلية، سنوات الخبرة، العمر، الدورات التدريبية)؟

أهمية الدراسـة:

تتمحور أهمية هذه الدراسة في تركيزها على ما يلي: تحديد الاحتياجات التدريبية لأعضاء الهيئة التدريسية إذ تعتبر هذه الفئة المحرك الأسساسي لتطوير وتحسين العملية التربوية والتعليمية وتحديد البرامج التدريبية المناسبة ضيمن منهج علمي منظم. تطوير مهارات، وقدرات وأداء أعضاء هيئة التدريس بناءً على متطلبات جودة التعليم الجامعي. التنسيق والتخطيط إلى برامج تدريبية تنبثق من احتياجات أعضاء هيئة التدريس.

محدددات الدراسـة:

الحدود الموضوعية: تناولت الدراسـة الاحتياجات التدريبية لأعضياء هيئة التدريس بجامعة تبوك في ضوء متطلبات جودة التعليم الجامعي.

الحدود البشرية: تم تطبيق الدراساة على أعضاء هيئة التدريس بجامعاة تبوك.

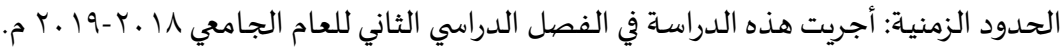
الحدود المكانية: جامعة تبوك بالمملكة العربية السعودية

مصطلحات الدراسـة: • التدريب: هي عملية منظمة ومخطط لها تهدف إلى زيادة المعارف والمهارات والقدرات لدى الموارد البشرية في المنظمة وتغيير اتجاهاتهم وسلوكياتهم بشكل يتناسب مع متطلبات جودة التعليم الجامعي في العصر الحالي (السالم والصالح، و . .ب). وفي هذه الدراسـة يُعرف التدريب على إنها تزويد أعضاء الهيئة التدريسية بالمهارات والمعارف والقدرات التي تؤهلهم لاستيعاب ومواكبة التغيير في الوسائل التكنولوجية والثقافية لتطوير وتحسين أدائها الأكاديمي. الاحتياجات التدريبية: هي عبارة عن مجموعة المعارف والمهارات والاتجاهات التي يحتاج لها الموظف من أجل أداء مهامه بكفاءة وفاعلية أكثر. وإجرائياً يمكن تعريفها بأها مجموعة التطورات والتغييرات المراد إحد اثها في مهارات واتجاهات وكفايات أعضاء الهيئة التدريسية (.الربيعي و النوري

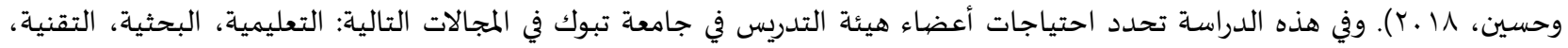
الجودة والاعتماد الأكاديمي، القيادية وتطوير الذات). 
جودة التعليم الجامعي: عرف عشيبة (. . ب) الجودة في التعليم على انها مجموعة من الخصائص والمعايير تتوافر في جميع عناصر العملية التعليمية والتي تلبي احتياجات منسوبي المؤسسة التعليمية وأفراد المجتمع ورغباتهم ومتطلباتهم وحاجاتهم وتحقيق تلك الخصيائص من خلال الاستخدام الفعَّال لجميع الموارد المادية والبشرية. وإجرائيا يمكن تعريف جودة التعليم الجامعي بأها عملية استراتيجية تقوم على العديد من القيم المؤسسية التي تمكن المؤسسات التعليمية من تنمية وتطوير قدرات العاملين فيها واستثمارها استثمارا إبداعياً يضمن تحقيق رسالة المؤسسة التعليمية والبحثية وخدمة المجتمع. أعضياء هيئة التدريس: هم الأشخاص الممارسون للعملية التربوية والأكاديمية والتعليمية في مختلف التخصصيات والكليات والحاصلين على درجة معيد، محاضر، أستاذ مساعد، أستاذ مشارك وأستاذ.

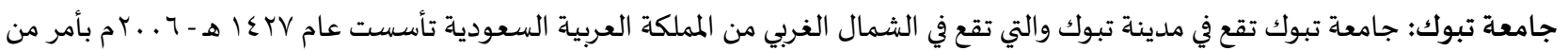
خادم الحرمين الشريفين الملك عبد الله بن عبد العزيز آل سعود، وتبلغ مساحة الحرم الجامعي للمدينة الجامعية با المليون متر مربع، وعدد

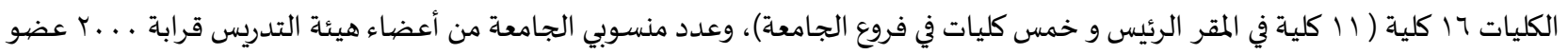
هيئة التدريس من مختلف الدرجات العلمية و . ع ألف طالب وطالبة في مختلف التخصصيات العلمية المختلفة، وقد حصلت مجموعة من برامج

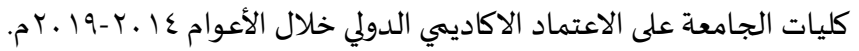

\section{الإطار النظري}

أولاً: التدريب والتطوير

تُعرف عملية التدريب (Training) على أهها عملية تزويد الموظفين بالمهارات والمعرفة المناسبة لتنفيذ وأداء عمل معين. وهو يُعد إجراء مخطط لله يهدف إلى تمكين الموظفين بالمعلومات والمهارات اللازمة لتحسين أداء الأفراد في المؤسسة. كما يمكن تعريفه بأنه نشاط منظم يدعم قدرة الإنسان لإنجاز هدف معين من خلال تزويده بالمهارات والمعلومات المناسبة. وفي تعريف أخر يعرف على أنه مجموعة المهارات والقواعد والمفاهيم والاتجاهات التي يتم

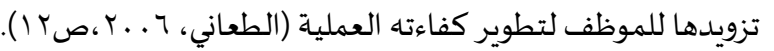
بينما التطوير (Development) يُعرّف على أنه عملية تستهدف العملية التي يتم بموجبها تتم المواءمة بين اهتمامات الفرد ومتطلباته في مسيرة

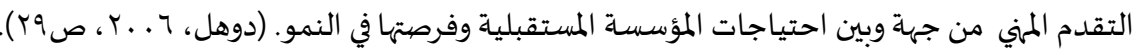
تهدف عملية التدريب إلى توثيق الاتصال بين أفراد المؤسسة والمؤسسة و تنمية روح الفريق وجعل الأفراد أكثر قدرة على الإبداع والابتكار مما

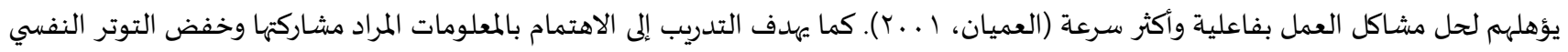
المصاحب للعمل وزيادة الثقة بالنفس للقيام بالأعمال دون مساعدة الآخرين وضمان تطابق معارف الموظفين وقدراتهم والتكييف مع متطلبات العمل

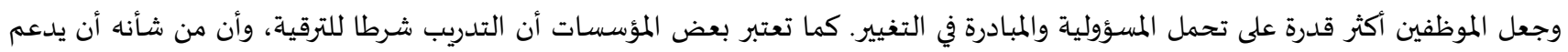

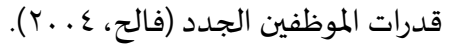

كما ذكر حنفي (r .r) أن أهمية التدريب تظهر في مستويين، الأول بالنسبة للمنظمة إذ أن التدريب يعود بمنافع وفوائد كبيرة مثل زيادة

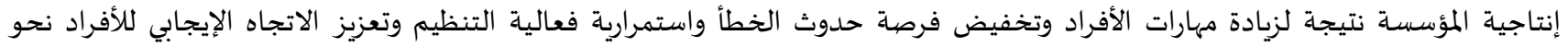
مؤسستهم وتوضيح سياسيات المنظمة. أما المستوى الثاني يعتبر التدريب ذا أهمية بالغة بالنسبة للموظفين إذ يلعب دورا مهما في تحسين فهمهم لطبيعة المنظمة وتعزيز فهمهم لأدوارهم وكما يساهم في رفع معنويات الموظف وتهيات وتحسين العلاقات الإنسانية داخل المؤسسة.

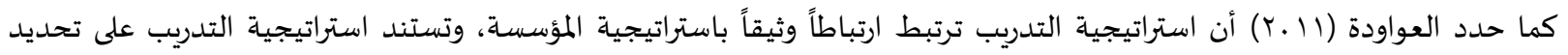

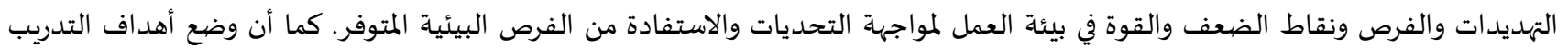

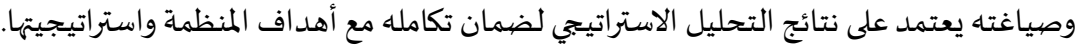

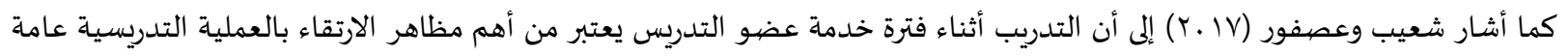
وبأداء المدرس من ناحية خاصة،، ونظرا لأهميته ارتأت بعض الجامعات من جعل التدريب شرطا لمزاولة المهنة نظراً لأهميته في مثل هذا العصبر الذي يضج بوفرة المعلومات وتراكمها بفترة قصيرة، إذ تم تطوير برامج تأهيل المعلم الجامعي وجعلها من مسؤوليات الجامعة التي تستقطب مختصين وخبراء مؤهلين لتنمية قدرات ومهارات المدرسين. كما حددت كل من حبيب وحسين (17 ـ (Y) معايير اختيار أعضاء هيئة التدريس كما يلي: المؤهلات ومستوى التدريب بالإضافة إلى خبراتهم

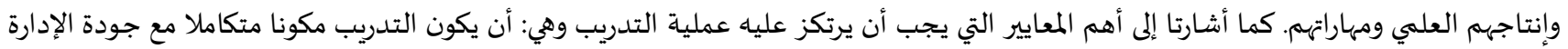

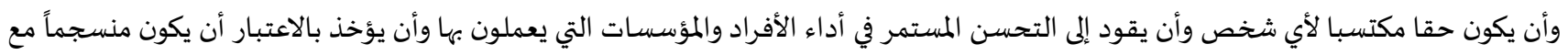

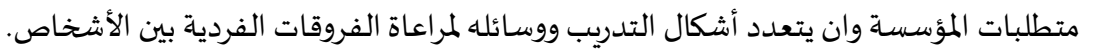
ومن الطرائق الشائعة في التدريب (الصيديق، 10 ـ. r): 
التدريب في موقع العمل : أكثر طرق التدريب شيوعاً إذ يقوم المدرب بتوجياه وتدريب العاملين الموجودين بالخدمة استنادا على خطوات معينة

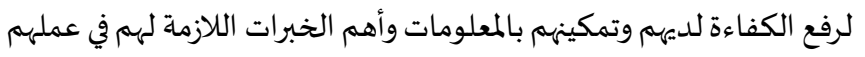
التناوب الوظيفي: نقل الموظفين من قسم إلى قسم آخر لتدريههم على طبيعة العمل في القسم المنقول لله مما يزيد من مهاراتهم وقدرتهم على إشغال أكثر من وظيفة خاصة في حالة الظروف الاستثنائية وفي حال نقص الخبرات في بعض الوظائف

التدريب خارج العمل في بيئة مماثلة: إذ يتم في بيئة مجهزة بجميع المعدات والمستلزمات الموجودة في مكان العمل الأصلي.

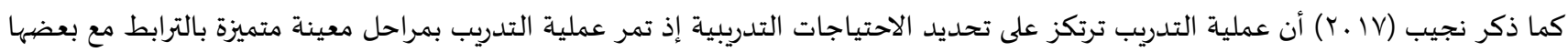
البعض ويتب مراعاة التسلسل فيها فلا يمكن تجاوز أي مرحلة، وتتضمن عملية التدريب المراحل التالية:

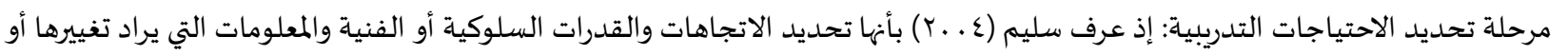

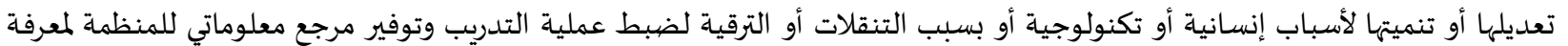
مشاكل الأداء. مرحلة تصميم البرامج التدريبية: يعتبر البرنامج التدريب مجموعة من الخطوات تهدف إلى تنظيم وتخطيط عملية التدريب للوصول للأهداف المتوقعة من التدريب وتشمل هذه المرحلة تحديد عنوان البرنامج التدريبي بشكل يتوافق مع الاحتياجات التدريبية وتحديد أهدافه ونوع المهارات

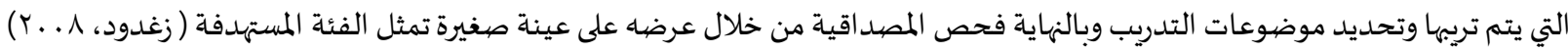
مرحلة تقييم البرامج التدرببية: وتشمل الإجراءات التي تتبعها الإدارة لقياس فاعلية البرنامج التدريبي ومدى تحقيقها للأهداف المرجوة منه وقياس كفاءة المتدرب قبل وبعد البرنامج التدريبي. إذ تتم عملية التقييم قبل تنفيذ البرنامج التدريبي وبعده ومتابعة النتائج بعد فترة معينة وتستخدم

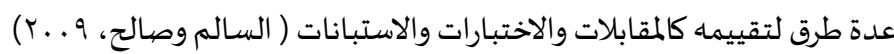
تعرف الاحتياجات التدريبية على إنها مجموعة التطورات والتغيرات المراد إحداثها بصورة إجابية في مهارات وسلوكيات ومعارف الموظفين للتغلب

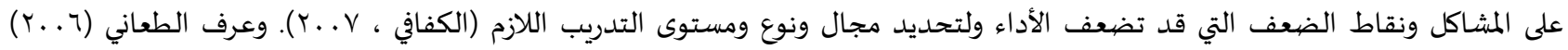

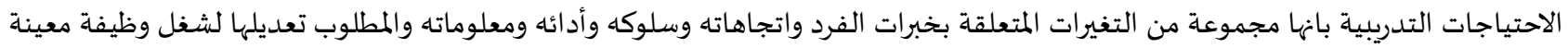

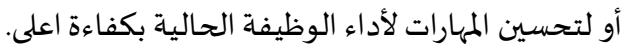

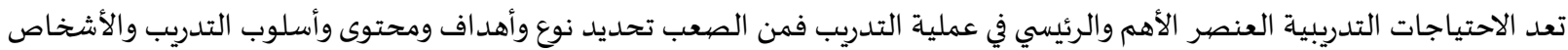
الخاضعين للتدريب بدون التحديد الدقيق للاحتياجات التدريبية. إذ تتمحور أهمية تحديد الاحتياجات التدريبية حول (الصديق، 10 ــץ):

$$
\begin{aligned}
& \text { • العامل الفعال الذي يوجاء التدريب نحو الاتجاهات المناسبة والصحيحة } \\
& \text { رفع كفاءة الموظفين في أداء مهامهه } \\
& \text { العنصر الأساسي الذي تقوم عليه أي نشاط تدريبي } \\
& \text { تساعد في توجياء الإمكانات المتوفرة للتدريب إلى الاتجاه الصحيح والسليم } \\
& \text { تخفيض النفقات } \\
& \text { تزيد من فرص ترقية الموظفين الحاليين وتوظيف عناصر جديدة } \\
& \text { توفير المال والجهد والوقت المبذول في التدريب } \\
& \text { تحديد الفئة التي يجب تدريبها }
\end{aligned}
$$

كما تهدف الاحتياجات التدريبية إلى مساعدة أعضياء الهيئة التدريسية بالاستمرار والاحتفاظ بمعدلاتلات الكفاءة ودعم المهارات وللكشف عن الكنات المشكلات التي يعانون منها ودراسة أسباهها للتغلب عليها ولتحقيق أهداف مبتكرة وغير عادية تحقق تميزا وتكسر الروتين وإحداث فروق جوهرية بأداء

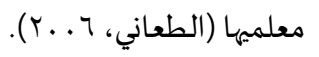

كما أوضح السديري وآخرون (rا ـ r) أن عملية تحديد الاحتياجات التدريبية هي عملية ديناميكية متغيرة من بيئة عمل إلى أخرى ومن فئة إلى فئة أخرى حسب خبرات وقدرات أعضاء الهيئة التدريسية والمستجدات والمتغيرات العالمية والمحلية لذلك يجب تحديد الاحتياجات التدريبية بصهورة دورية لتتلاءم مع متغيرات ومتطلبات العصر وهذا يتطلب من أعضاء هيئة التدريس مواكبة التطور عن طرق البرامج التدريبية. ثانياً: جودة التعليم الجامعي في ضوء التسارع في عصر العولمة، دفع أعضياء هيئة التدريس بمؤسسات التعليم العالي السعودية عامة وجامعة تبوك خاصة إلى مواكبة التغيرات والتطور والتقدم لمواجهة التحديات الحديثة إذ يرتبط مواكبة هذه التغيرات بقدرة أعضاء هيئة التدريس بالمحافظة على أدائهم ومهاراتهم

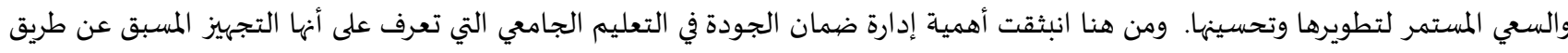


توفير المهارات السلوكية والإدراكية والفنية اللازمة لاستخدام الموارد القانونية والبشرية والزمنية والمادية المتاحة والتحول الفعال من الواقع الحالي إلى

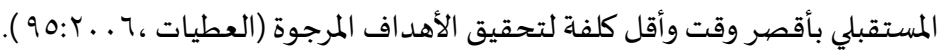

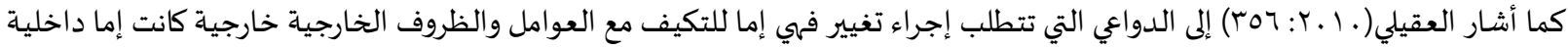

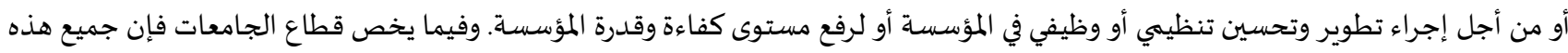
الدواعي تنبثق منها ضرورة إدارة ضراء إهمان الجودة.

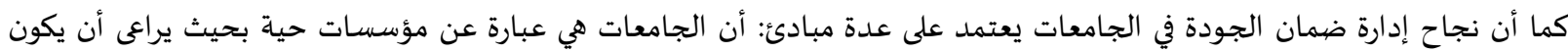

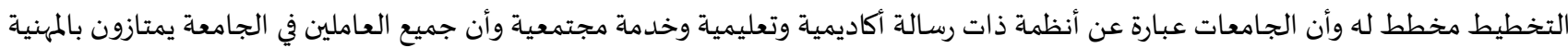

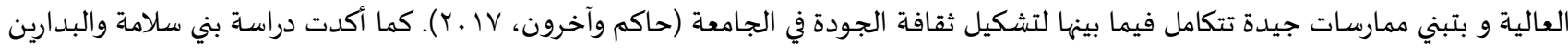

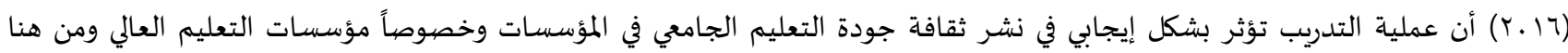
استدعت الحاجة إلى إعداد برامج تدريبية لتأهيل أعضياء هيئة التدريس.

وقد تناولت العديد من الدراسـات الاحتياجات التدريبية لأعضاء هيئة التدريس وأهمية التدريب والتطوير فئدية في جودة التعليم الجامعي: في دراسة قام بها (أبو نمرة والحديدي، 9 . . Y) بعنوان: الحاجات التدريبية لأعضاء الهيئات التدريسية في كليات العلوم التربوية في الجامعات الأردنية الخاصية. هدفت الدراسة إلى معرفة فيما إذا هناك فروث فردية تتعلق بمستوى إدراك ومعرفة أعضاء هيئة التدريس لاحتياجاتهم

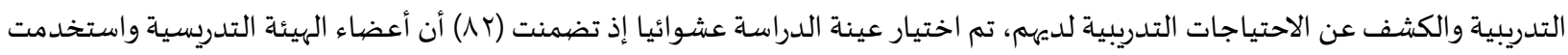

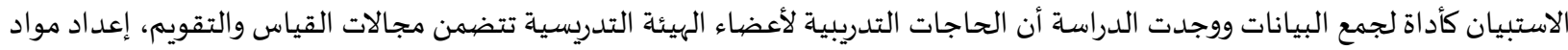

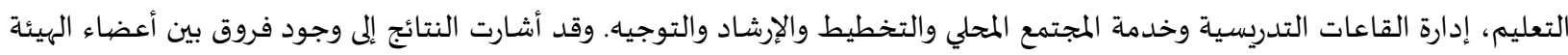
التدريسية بمستوى تقديرهم لحاجتهم التدريبية إلى التخطيط وإدارة قاعـة التدريس تعزى إلى الرتبة الأكاديمية.

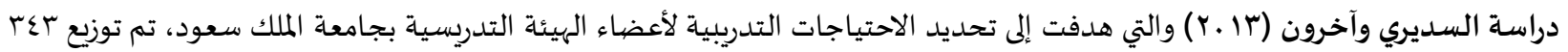

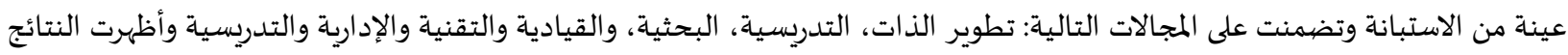
أن من اهم الاحتياجات التدريسية لدى أعضاء هيئة التدريس هي تصيميم وتخطيط التدريس تبعا لمعايير جودة التعليم الجامعي واتباع الأساليب

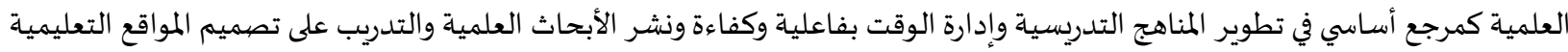
وتفعيل معايير التعليم الإلكتروني.

وفي دراسـة أعدها التويجري (Vا ـ r) والتي هدفت إلى تحديد العلاقة بين الاحتياجات التدريبية وإدارة المعرفة وتسويق جودة الخدمة التعليمية،

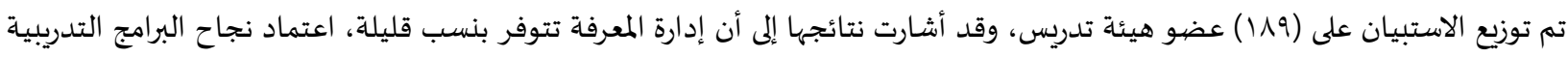

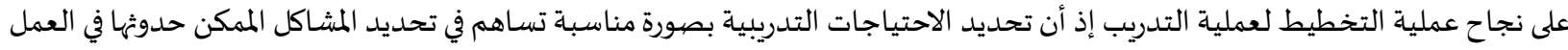

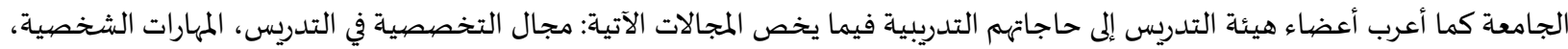
تنمية الموارد البشرية ومهارات القيادة والإدارة الجامعية.

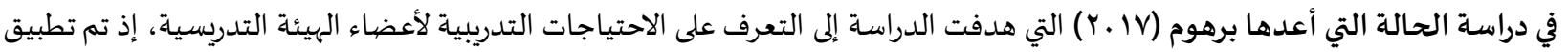
الاستبيان على (اه) عضو هيئة تدريس وأظهرت نتائج التحليل الإحصائي إلى أن حاجة الهيئة التدريسية تنحصرئ في المجالات التاتيات التالية: المهارات

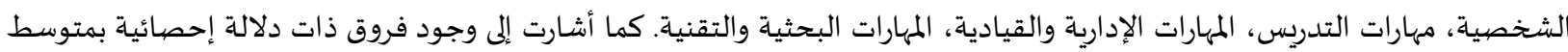

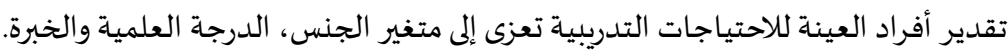
قام سرحان (Y) (Y) بإجراء دراسة لتحديد حاجات أعضاء التدريس للبرامج التدريبية ومعرفة فيما إذا هناك تأثير لمتغيرات الجنس، الخبرة،

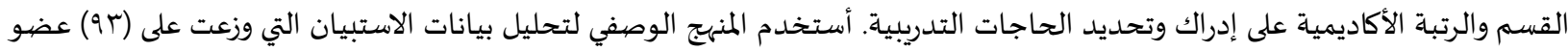

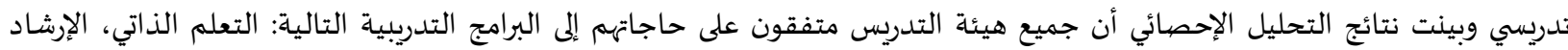

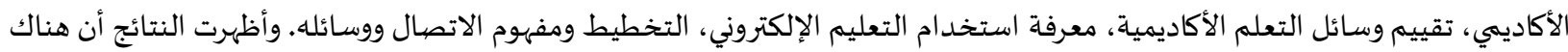

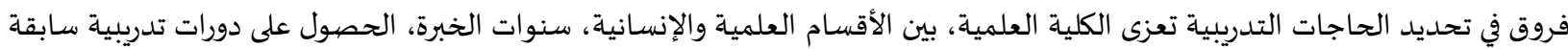
والرتبة الأكاديمية.

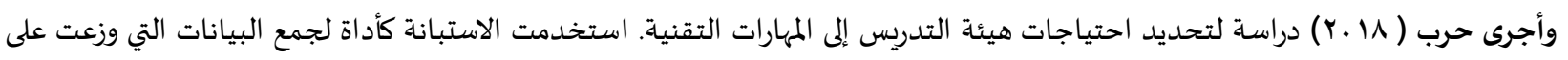

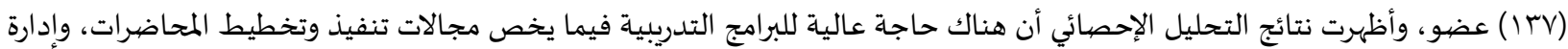
مشروعات البحث العلمي وبرامج التدريس والتقويم وأوصت الدراسة بضرورة تحديد حاجات أعضاء أتساء هيئة التدريس التدريبي قبل عقد أي دورة تدريب وتوفير دراسات بشكل دوري تتعلق بحاجات أعضاء الهيئة التدريسية لتحقيق الفاعلية والكفاءة للدورات التدريبية. 
وهدفت دراسـة (Diaz et al, 2009) إلى معرفة أعضاء هيئة التدريس ومواقفهم حول التغييرات في التعليم العالي في أوروبا وكيف يمكن تحسين النهج الحالية للتنمية المهنية على المستوى الجامعي. تشير النتائج من ناحية إلى وجود درجة من الجهل فيما يتعلق بالتغييرات في التعليم العالي

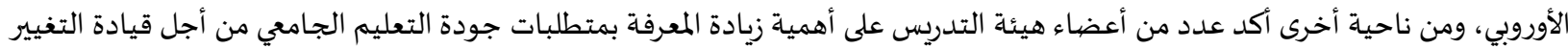

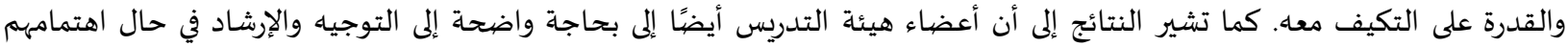
باستراتيجيات التعلم الجديدة. وهدفت دراسـة (Nguyen et al, 2011) إلى لتحديد مدى معرفة أعضياء هيئة بالاحتياجات التدربية المرتبطة بالتعلم عن بعد ، والمحاكاة ، والرعاية الصحية عن بعد ، وأدوات المعلوماتية في تعليم التمريض وممارسته، تم توزيع الاستبيان ل (ب (19) من أعضاء هيئة التدريس في كليات

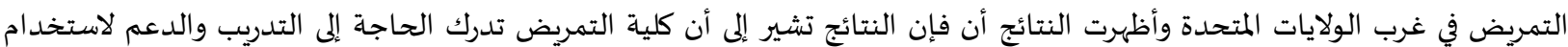
التقنيات التعليمية بفعالية وكفاءة. (Nasreen, 2012) هدفت إلى وضع كلية التدريب والتطوير في جامعات القطاع العام في البنجاب، هدفت الدراسة إلى معرفة الممارسات الحالية لتدريب أعضياء هيئة التدريس وتطويرها في جامعات القطاع العام القديمة والحديثة في البنجاب ، باكستان. شملت عينة

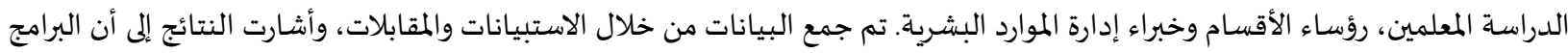

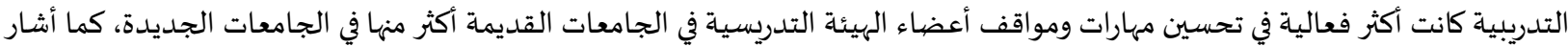
مديري الموارد البشرية إلى تقطع تنفيذ البرامج التدريبية داعين إلى ضرورة التخطيط المنظم والمحدث لهاء.

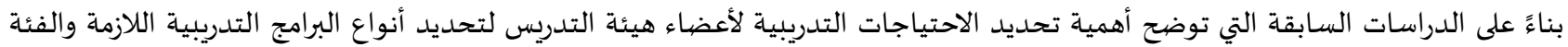
المستهدفة للتزويد أعضياء التدريس بالمهارات المهنية اللازمة للقيام بأعمالهم. تهدف هذه الدراسة إلى تحديد الاحتياجات التدريبية لأعضاء هيئة التدريس في جامعة تبوك في ضوء متطلبات جودة التعليم الجامعي.

$$
\text { أولاً منههجية الدراسـة: الدراسـة وإجر ائتها: }
$$

تم استخدام المنهج الوصفي الملائمته لهدف الدراسـة والذي يتمثل في تحديد الاحتياجات التدربية لأعضياء الهيئة التدريسية في جامعة تبوك

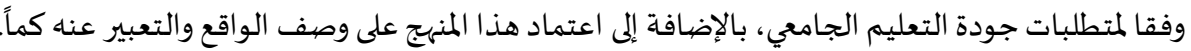

ثانياً حدود الدراسة:

الحد الزماني في ضوء سعي الباحث لتحقيق هدف هذه الدراسة، استغرق تنفيذ الدراسة ستة أشهر في عام 19 ــ م. الحد المكاني حيث تم تطبيق الدراسـة في جامعة تبوك بمدينة تبوك في المملكة العربية السعودية.

الحد البشري تكون مجتمع الدراسة من جميع أعضاء الهيئة التدريسية في جامعة تبوك (ذكور وإناث) في العام الجامعي 19 ـ. .

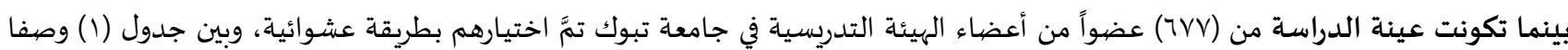
لأفراد عينة الدراسة وفقا لمتغيرات (النوع، الدرجة العلمية، عدد سنوات العمل بات بالجامعة، اسم الكلية التابع لها، هل سبق أن التحقت بإحدى الدورات التدرببية المقدمة من جامعة تبوك):

\begin{tabular}{|c|c|c|}
\hline النسبة المئوية & العدد & الجنس \\
\hline$\varepsilon \wedge, \uparrow$ & rrq & ذكر \\
\hline $01, \varepsilon$ & $r \leqslant \Lambda$ & أنثى \\
\hline $1 \ldots$, & TVV & المجموع \\
\hline
\end{tabular}

جدول(1) (1) توزيع عينة الدراسة وفقاً لمتغير النوع

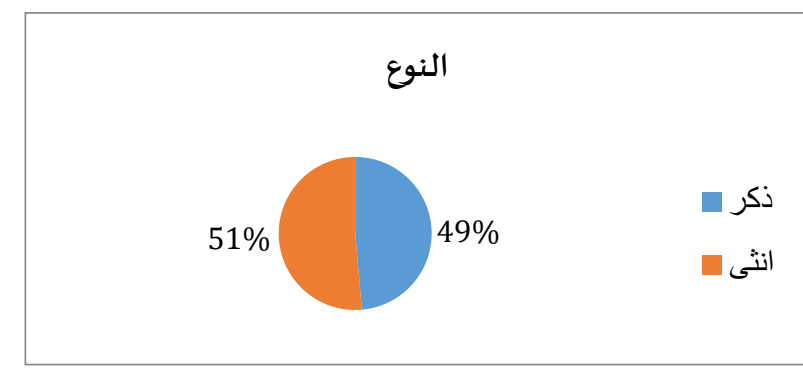

الشكل(1): توزيع أفراد العينة تبعاً لمتغير النوع 


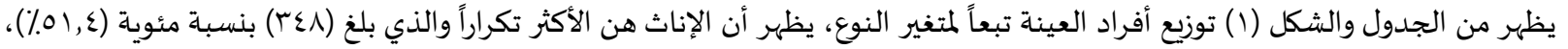

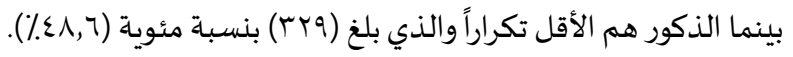

جدول (Y): توزيع عينة الدراسة وفقاً لمتغير عدد سنوات العمل بالجامعة

\begin{tabular}{|c|c|c|}
\hline النسبة المئوية & العدد & الفئة الفئ \\
\hline $79, \varepsilon$ & $\varepsilon \gamma$. & أقل من ه سنوات \\
\hline$r \eta, \varepsilon$ & 189 & من ه-.. سنوات \\
\hline$\varepsilon, 1$ & ru & أكثر من · ا سنوات \\
\hline$\cdot$ & TVV & المجموع \\
\hline
\end{tabular}

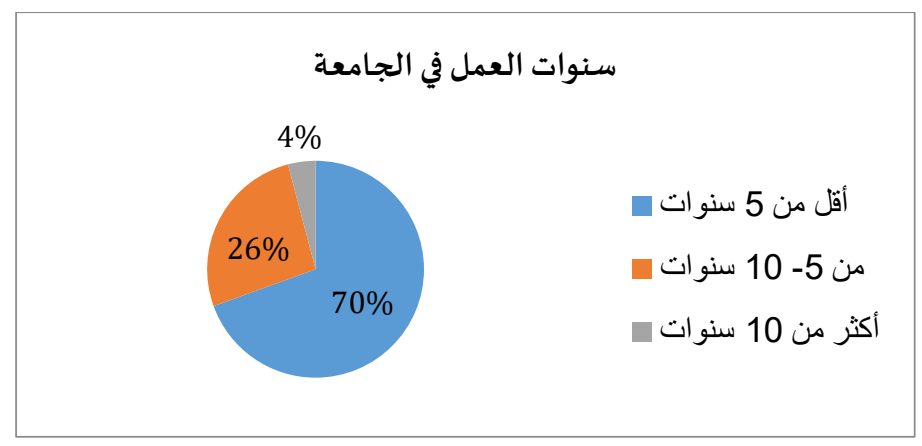

الشكل (Y): توزيع أفراد العينة تبعاً لمتغيرسنوات العمل بالجامعة

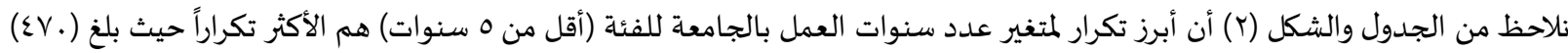

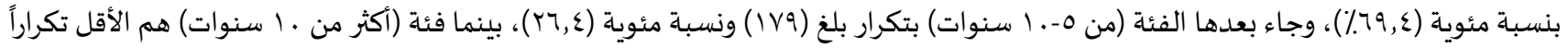

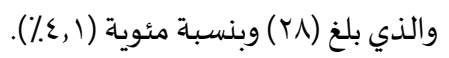
هل سبق أن التحقت بإحدى الدورات التدريبية المقدمة من جامعة تبوك

جدول(r): توزيع عينة البحث وفقاً لمتغير الالتحاق بالدورات التدريبية

\begin{tabular}{|c|c|c|}
\hline النسبة المئوية & العدد & الفئة \\
\hline$r, r$ & $10 \mathrm{r}$ & ل \\
\hline $\mathrm{V}\urcorner, \wedge$ & or. & نعم \\
\hline $1 \ldots$, & TVV & المجموع \\
\hline
\end{tabular}

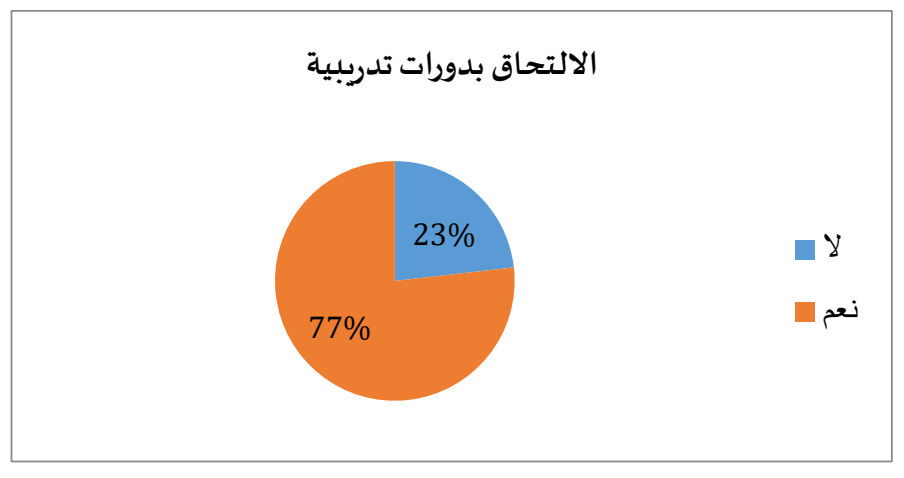

الشكل(r): الدورات التدريبية لدى عينة البحث

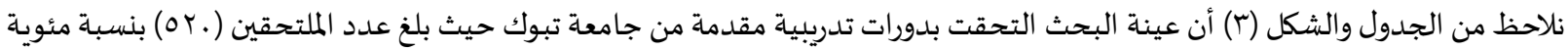

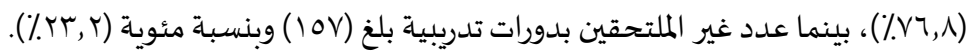


جدول(ع): توزيع عينة الدراسة وفقاً للمتغير اسم الكلية التابع لها

\begin{tabular}{|c|c|c|c|}
\hline النسبة المئوية & العدد - العد & | ل الكلية & 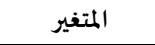 \\
\hline $1 .,$. & 71 & الكلية الجامعية بمحافظة الوجه & \multirow[t]{17}{*}{ ل ل لكلية التابع لها } \\
\hline$V, \varepsilon$ & 0 . & الكلية الجامعية بمحافظة أملج & \\
\hline $1, r$ & $\Lambda$ & الكلية الجامعية بمحافظة ضباء & \\
\hline$v, 1$ & $\varepsilon \wedge$ & الكلية الجامعية بمحافظة تيماء & \\
\hline$\Lambda, \mathrm{V}$ & 09 & الكلية الجامعية بمحافظة حقل & \\
\hline 0,1 & rq & 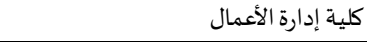 & \\
\hline $1 T, 9$ & $\wedge \mathrm{V}$ & كلية التربية والآداب & \\
\hline$r, 0$ & $r \varepsilon$ & كلية الحاسبات وتقنية المعلومات & \\
\hline $\mathrm{v}, \mathrm{\Lambda}$ & or & كلية الشريعة والأنظمة & \\
\hline$r, 1$ & r) & كلية الصيدلة & \\
\hline$\varepsilon, 1$ & ru & كلية الطب & \\
\hline $1 r, 9$ & $9 \varepsilon$ & 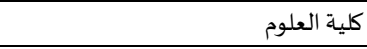 & \\
\hline$r, 1$ & r) & كلية العلوم الطبية التطبيقية & \\
\hline$r, 0$ & iv & كلية الفنون والتصاميم (الاقتصاد المنزلي) & \\
\hline$r, \Lambda$ & r7 & كلية المجتمع & \\
\hline $0,$. & $r \varepsilon$ & كلية الهندسة & \\
\hline $1 \ldots$, & TVV & المجموع & \\
\hline
\end{tabular}

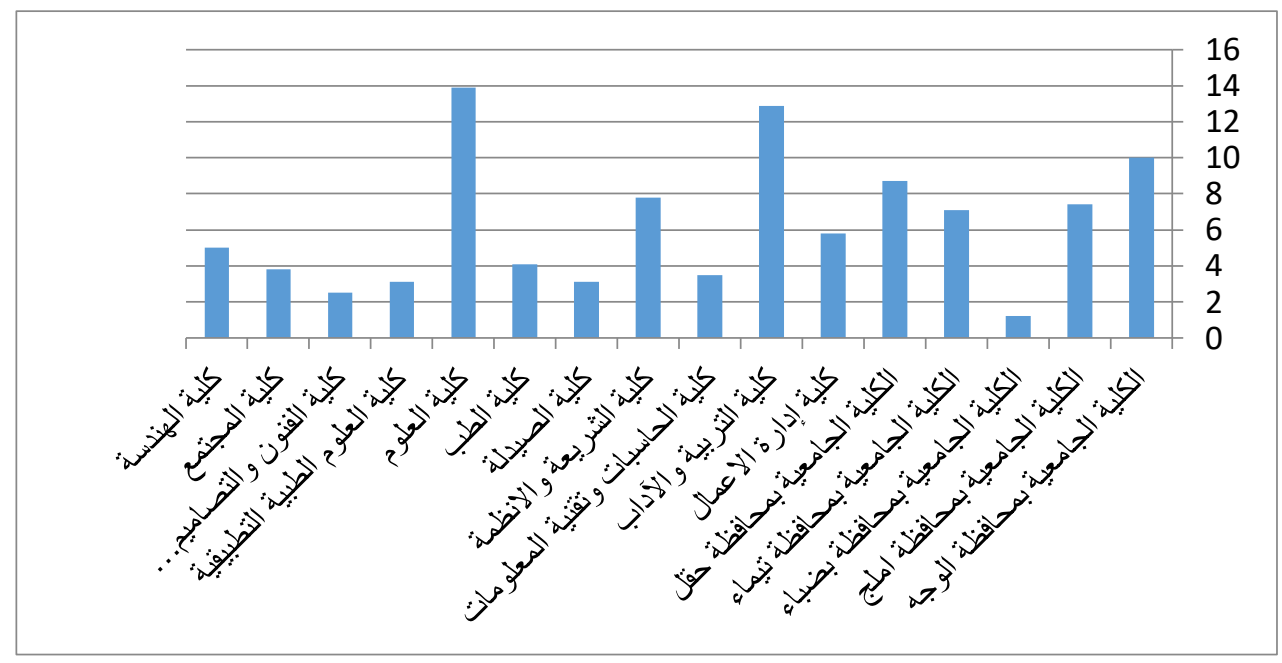

الشكل(ع): الكلية التابع لها لدى عينة البحث

يظهر من الجدول والشكل (ع) أن أبرز تكرار لمتغير اسم الكلية التابع لها بلغ (ع) بنسبة مئوية (q,؟1\%) لكلية العلوم، وجاءت بعدها كلية

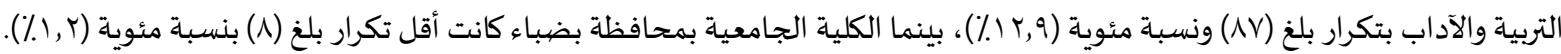

جدول(0): توزيع عينة الدراسة وفقاً لمتغير الدرجة العلمية

\begin{tabular}{|c|c|c|}
\hline النسبة الممئوية & العدد & الفئة \\
\hline$v, 0$ & 01 & معيد \\
\hline IT,. & 11 & محاضر \\
\hline $07, £$ & rAT & أستاذ مساعد \\
\hline$r \cdot, 0$ & 149 & أستاذ مشارك \\
\hline$r, 0$ & $r \varepsilon$ & أستاذ \\
\hline $1 \ldots$, & $T V V$ & المجمموع \\
\hline
\end{tabular}

• متغير الدرجة العلمية 


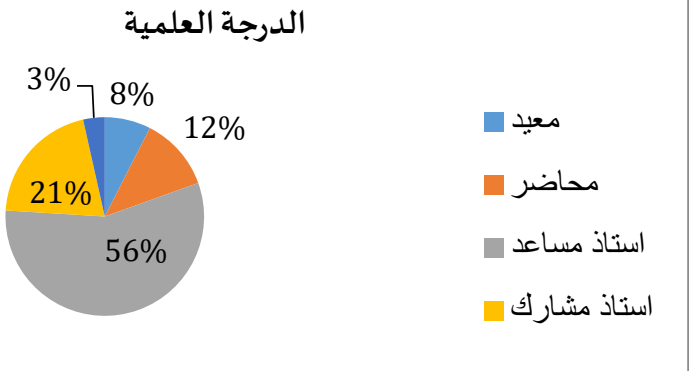

الشكل(0): توزيع أفراد العينة تبعاً لمتغير الدرجة العمية

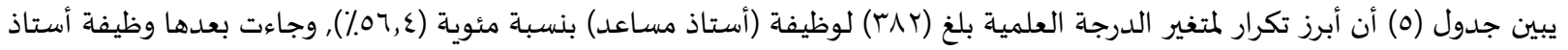

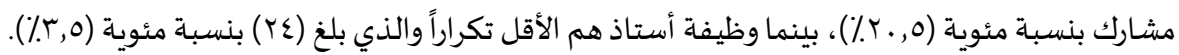
أدوات الدراسـة: صممت الاستبيان لجمع البيانات اللازمة لتحديد احتياجات أعضياء الهيئة التدريسية في جامعة تبوك. 1. صداق المحكمين:

عرضت الاستبانة الأولية على مجموعة من الأساتذة المحكمين وعددهم 10 محكماً من مختلف التخصصيات (النظرية والعلمية والصحية) في جامعة تبوك بمختلف الرتب الأكاديمية وقد أحذ بعين الاعتبار التعديلات المقترحة وتضمنت الاستبيان بشكله النهائي (1)) عبارة موزعة على محاور الاحتياجات التدريبية ومحاور إدارة التغيير. r. الثبات: للتحقق من ثبات أداة الدراسة تم تطبيق الأداة على عينة استطلاعية مكونه من .ع عضيواً من أعضياء هيئة التدريس في جامعة تبوك تمَّم اختيارهم من خارج العينة الأصلية، وتمَّ حساب معادلة الاتساق الداخلي بطريقة (ألفا كرونباخ) كثبات للتجانس، الجدول (7) يوضح ذلك.

جدول(7): معامل الاتساق الداخلي لأداة الدراسة

\begin{tabular}{|c|c|c|}
\hline معامل كرونباخ ألفا & عدد الفقرات & المحور \\
\hline .,$\Lambda \varepsilon$. & v & مهارات شخصية \\
\hline., 941 & ir & المهارات البحثية \\
\hline., 194 & $\mathrm{v}$ & ههارات الجودة والاعتماد الأكاديمي \\
\hline., $9 r$. & 9 & المهارات التعليمية \\
\hline., $91 \mathrm{~V}$ & 1. & المهارات التقنية \\
\hline$\cdot, 4 r q$ & 1. & المهارات القيادية \\
\hline., 971 & 07 & الأداة ككل \\
\hline
\end{tabular}

يظهر من جدول (7) أن قيم معاملات ألفا كرونباخ لمحاور الدراسة تراوحت بين (qrی, ....ب9, .)، كان أعلاها لمحور " المهارات التعليمية "، وأدناها لمحور " المهارات القيادية"، وبلغ معامل ألفا كرونباخ للأداء ككل (ا7جو, •) وجميع معاملات الثبات مرتفعة ومقبولة لأغراض الدراساة، حيث يعتبر معامل الثبات (ألفا كرونباخ) مقبول إذا زاد عن (.V. . • )وهي قيم مرتفعة ومقبولة لأغراض تطبيق الدراسة.

المعالجـة الإحصبائية:

تم استخدام برنامج التحليل الإحصائي SPS 20 لتحليل البيانات من خلال الاختبارات الآتية: النسب المئوية، التكرارات، والانحرافات المعيارية والمتوسطات الحسابية واختبار One-Way ANOVA واختبار Independent- Samples T-Test.

\begin{tabular}{|c|c|}
\hline \multicolumn{2}{|c|}{ جدول(V): حسـاب المتوسط المرجح } \\
\hline 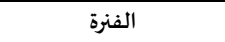 & المحور \\
\hline أقل من 1, 1, أ & ضعيف \\
\hline من T7, إلى أقل من r r, & متوسطة \\
\hline من rr,r حتى r & كبيرة \\
\hline
\end{tabular}

جدول (V) يبين حساب المتوسط الحسابي المرجح لفقرات الاستبانة المستخدمة لجمع البيانات للدراسة. 


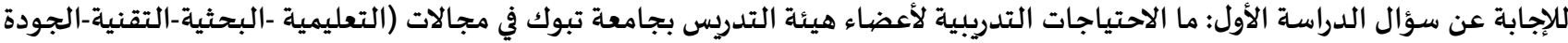

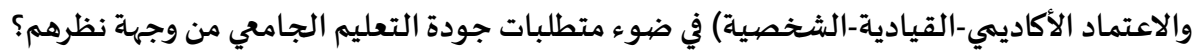

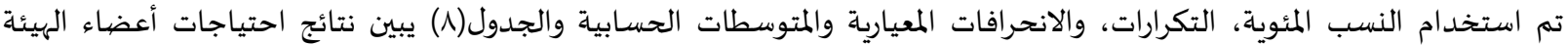
التدريسية في المجالات الشخصية: جدول(^): الاحتياجات التدرببية لأعضياء الهيئة التدريسية

\begin{tabular}{|c|c|c|c|c|c|c|}
\hline \multirow[t]{2}{*}{ المتوسط } & \multicolumn{3}{|c|}{ درجة الحاجة } & & \multirow[t]{2}{*}{ الحاجة التدرببية } & \multirow[t]{2}{*}{ 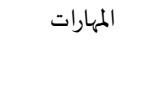 } \\
\hline & 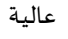 & متوسطة & منخفضية & & & \\
\hline \multirow[b]{2}{*}{$r, \varepsilon r$} & 011 & $1 \leqslant 9$ & IV & ك & \multirow[t]{2}{*}{ مهارات التخطيط والتنظيم } & \multirow{4}{*}{ مهارات شخصية } \\
\hline & vo,o & Tr & $r, 0$ & $\%$ & & \\
\hline \multirow[b]{2}{*}{$r, 00$} & 197 & 197 & r & ك & \multirow[t]{2}{*}{ قيادة وإدارة التغيير } & \\
\hline & $T V, V$ & rq & $r, \varepsilon$ & $\%$ & & \\
\hline \multirow[t]{2}{*}{ المتوسط } & \multicolumn{3}{|c|}{ درجة الحاجة } & & \multirow[t]{2}{*}{ الحاجة التدريبية } & \multirow{12}{*}{ مهارات شخصية } \\
\hline & 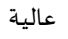 & متوسطة & منخفضية & & & \\
\hline \multirow[b]{2}{*}{$r, 7 \varepsilon$} & $\varepsilon 17$ & בוד & To & ك & \multirow[t]{2}{*}{ بناء فريق العمل } & \\
\hline & $71, \varepsilon$ & $r \varepsilon, q$ & $r, \mathrm{~V}$ & $\%$ & & \\
\hline \multirow[b]{2}{*}{$r, 00$} & $\varepsilon \wedge 1$ & ivo & YI & ك & \multirow[t]{2}{*}{ الابتكاروالإبداع القيادي } & \\
\hline & vi & ro, & $r, 1$ & $\%$ & & \\
\hline \multirow[b]{2}{*}{$r, 00$} & $\varepsilon .1$ & $T \leq 0$ & r & ك & \multirow[t]{2}{*}{ إدارة المبادرات المجتمعية } & \\
\hline & $09, Y$ & r., r & $\varepsilon, 7$ & $\%$ & & \\
\hline \multirow[b]{2}{*}{$r, Y$} & $0 . r$ & $1 \leqslant 9$ & ry & ك & \multirow{2}{*}{ استراتيجية الإقناع والتأثيرفي البيئة } & \\
\hline & $V \varepsilon, r$ & rt & $r, \Lambda$ & $\%$ & & \\
\hline \multirow[b]{2}{*}{$r, \varepsilon r$} & r人E & $r \cdot r$ & 9. & ك & \multirow[t]{2}{*}{ كتابة التقاريروالمحاضرات } & \\
\hline & $07, \mathrm{~V}$ & $r$. & $1 r, r$ & $\%$ & & \\
\hline
\end{tabular}

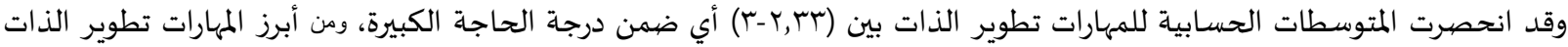

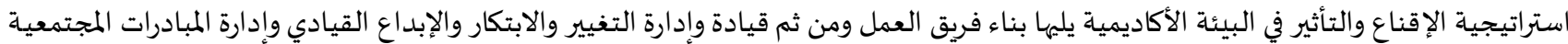
و مهارات التخطيط والتنظيم و كتابة التقارير والمحاضرات. بينما يظهر الجدول (9) الاحتياجات التدريبية لأعضاء الهيئة التدريسية في المجالات التئات البحثية:

جدول(9): الاحتياجات التدريبية لأعضاء الهيئة التدريسية في المجالات البحثية

\begin{tabular}{|c|c|c|c|c|c|c|}
\hline \multirow[t]{2}{*}{ المتوسط } & \multicolumn{3}{|c|}{ درجة الحاجة } & & \multirow[t]{2}{*}{ الحاجة التدريبية } & \multirow{18}{*}{ المهارات } \\
\hline & عالية & متوسطة & منخفضة & & & \\
\hline \multirow[b]{2}{*}{ r, $乏 १$} & rva & rt. & 09 & ك & \multirow[t]{2}{*}{ استخدام قواعد البيانات ومحركات البحث } & \\
\hline & 07 & rT,O & $\Lambda, \mathrm{V}$ & $\%$ & & \\
\hline \multirow[b]{2}{*}{$r, 01$} & $r q \varepsilon$ & r... & $7 \varepsilon$ & ك & \multirow[t]{2}{*}{ البحوث الكمية } & \\
\hline & $0 \wedge, r$ & $r 9,0$ & 9,0 & $\%$ & & \\
\hline \multirow[b]{2}{*}{$r, 0$} & rqs & r... & $7 \varepsilon$ & ك & البحوث النوعي البحي & \\
\hline & $0 \Lambda, Y$ & $r 9,0$ & 9,0 & $\%$ & & \\
\hline \multirow[b]{2}{*}{$r, \lambda 1$} & rוד & r19 & V7 & ك & \multirow[t]{2}{*}{ تصيميم الاستبانات } & \\
\hline & or, 7 & rt,r & $11, r$ & $\%$ & & \\
\hline \multirow[b]{2}{*}{ T,乏૫ } & r. & $r \leq 1$ & ov & ك & \multirow[t]{2}{*}{ تصميم المقابلة البحثية } & \\
\hline & or, r & ro,7 & $\wedge, \varepsilon$ & $\%$ & & \\
\hline \multirow[b]{2}{*}{$r, 01$} & $\varepsilon r$ & 191 & $\varepsilon 0$ & ك & \multirow[t]{2}{*}{ الكتابة التحليلية النقدية } & \\
\hline & $7 r, r$ & TA, & 7,7 & $\%$ & & \\
\hline \multirow[t]{2}{*}{$r, 00$} & $\varepsilon .9$ & t.r & $\leqslant 7$ & ك & \multirow[t]{2}{*}{ نظام Latex لتنسيق الورقة العلمية } & \\
\hline & $7 ., \varepsilon$ & $r$. & 7,1 & $\%$ & & \\
\hline \multirow[t]{2}{*}{ المتوسط } & & 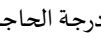 & & & \multirow[t]{2}{*}{ الحاجة التدريبية } & \\
\hline & عالية & متوسطة & منخفضة & & & \\
\hline
\end{tabular}




\begin{tabular}{|c|c|c|c|c|c|c|}
\hline \multirow[t]{2}{*}{$r, 7$} & $\varepsilon r \wedge$ & 187 & $\varepsilon \varepsilon$ & ك & \multirow[t]{2}{*}{ برامج توثيق المراجع مثل Endnote } & \\
\hline & $7 \varepsilon, V$ & r & 7,0 & $\%$ & & \\
\hline \multirow[t]{2}{*}{$r, 01$} & $r 97$ & r.r & 7. & ك & \multirow[t]{2}{*}{ الأسـاليب الإحصيائية في البحوث الكمية } & \\
\hline & $0 \wedge, 0$ & $r 9,1$ & 1,9 & $\%$ & & \\
\hline \multirow[t]{2}{*}{$r, \leqslant 7$} & $\varepsilon 19$ & 119 & 0. & ك & \multirow[t]{2}{*}{ تحليل البيانات في البحوث النوعية } & \\
\hline & 71,9 & $r V, q$ & $\vee, \varepsilon$ & $\%$ & & \\
\hline \multirow[t]{2}{*}{$r, 0$} & $r 9 \Lambda$ & $19 \varepsilon$ & 77 & ك & \multirow[t]{2}{*}{ SPSS برنامج } & المهارات البحثية \\
\hline & $0 \wedge, \wedge$ & $r \wedge, V$ & $9, \vee$ & $\%$ & & \\
\hline \multirow[t]{2}{*}{$r, \sum 7$} & rel & YIM & 79 & ك & \multirow[t]{2}{*}{ 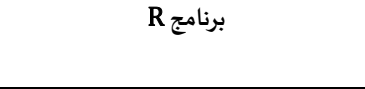 } & \\
\hline & $0 \leqslant, 1$ & $r, r$ & $1 ., r$ & $\%$ & & \\
\hline \multirow[t]{2}{*}{$r, \wedge 1$} & $0 \leqslant 0$ & $1 . r$ & 1. & ك & \multirow[t]{2}{*}{ النشر العلمي والمجلات العلمية } & \\
\hline & 1., 0 & $10, r$ & 1,0 & $\%$ & & \\
\hline
\end{tabular}

وفي المجال البحثي نجد أن اهتمام أعضاء الهيئة التدريسية فيما يخص المهارات البحثية له أهمية مرتفعة اذا أن مهارات النشر العلمي والمجلات

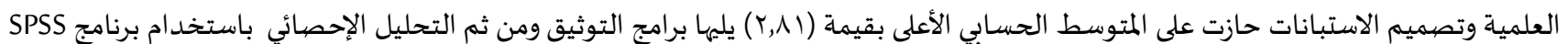
والأساليب البحثية الكمية والنوعية وإعداد الابحاث التابعة لها وكيفية تحليلهات التانيا. في حين يوضح الجدول (. () نتائج التحليل الوصفي لاحتياجات أعضاء التدريس وفقا للمجالات التات التعليمية: جدول( ـ (): الاحتياجات التدريبية وفقاً للمجالات التعليمية

\begin{tabular}{|c|c|c|c|c|c|c|}
\hline \multirow[t]{2}{*}{ المتوسط } & \multicolumn{3}{|c|}{ 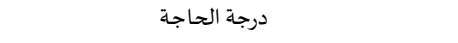 } & & \multirow[t]{2}{*}{ الحاجة التدريبية } & \multirow{24}{*}{ مهارات الجودة } \\
\hline & عالية & متوسطة & منخفضية & & & \\
\hline \multirow[b]{2}{*}{ r,Tr } & $\varepsilon r V$ & $1 \wedge \mathrm{V}$ & rt & ك & \multirow[b]{2}{*}{ التخطيط الاستر اتيجي ومؤشرات الأداء } & \\
\hline & $7 \varepsilon, 0$ & $r V, T$ & $\varepsilon, V$ & $\%$ & & \\
\hline \multirow[b]{2}{*}{ r,OV } & $\varepsilon r \varepsilon$ & IVE & 01 & ك & \multirow[b]{2}{*}{ الاعتمادات الأكاديمية البرامجية الدولية } & \\
\hline & $7 r, 7$ & ro,V & $\checkmark, 0$ & $\%$ & & \\
\hline \multirow[b]{2}{*}{ r,Tr } & $\varepsilon 09$ & 1ro & 00 & ك & \multirow[t]{2}{*}{ الاعتماد الأكاديمي البرامجي الوطني } & \\
\hline & $7 \mathrm{~V}, \mathrm{\Lambda}$ & 19,9 & $\Lambda, 1$ & $\%$ & & \\
\hline \multirow[b]{2}{*}{$r, \varepsilon \wedge$} & ror & ris & 70 & ك & \multirow[b]{2}{*}{ تسجيل المؤهلات } & \\
\hline & or, 1 & or, r & 9,7 & $\%$ & & \\
\hline \multirow[b]{2}{*}{$r, 09$} & rat & TrY & $\varepsilon \wedge$ & ك & \multirow[b]{2}{*}{ 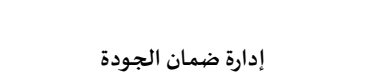 } & \\
\hline & $07, \varepsilon$ & $r T, \varepsilon$ & $v, 1$ & $\%$ & & \\
\hline \multirow[b]{2}{*}{$r, 00$} & rیl & THV & $\varepsilon \wedge$ & ك & \multirow{2}{*}{ توصيف البرنامج وفقاً لمواصفات الجودة } & \\
\hline & $07, r$ & Tr,o & $V, 1$ & $\%$ & & \\
\hline \multirow[b]{2}{*}{$r,\{\wedge$} & $\varepsilon \cdot 1$ & T.7 & $\varepsilon r$ & ك & \multirow{2}{*}{ 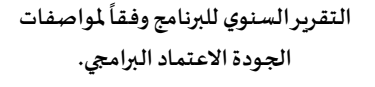 } & \\
\hline & $7 ., r$ & $r_{\cdot}, \varepsilon$ & $7, r$ & $\%$ & & \\
\hline \multirow[t]{2}{*}{ المتوسط } & \multicolumn{3}{|c|}{ درجة الحاجة } & & \multirow[t]{2}{*}{ الحاجة التدربيية } & \\
\hline & 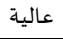 & متوسطة & منخفضية & & & \\
\hline \multirow[b]{2}{*}{ r,07 } & rat & $r \varepsilon V$ & $\varepsilon V$ & ك & \multirow{2}{*}{ لمواصفريرات الجودة الاعنوي لأعمال العمادات وفقاً } & \\
\hline & or,o & ra,o & 7,9 & $\%$ & & \\
\hline \multirow[b]{2}{*}{$r, 00$} & $\varepsilon .0$ & $r \cdot \varepsilon$ & $\varepsilon V$ & ك & \multirow{2}{*}{ تقرير المقرروفقاً لمواصفات الجودة الاعتماد } & \\
\hline & 09,1 & $r ., 1$ & 7,9 & $\%$ & & \\
\hline \multirow[t]{2}{*}{$r, 09$} & $\varepsilon r \varepsilon$ & ivo & $\varepsilon V$ & ك & \multirow[t]{2}{*}{ أنظمة التطويروالجودة الإلكترونية } & \\
\hline & $7 \varepsilon, 1$ & ro,A & 7,9 & $\%$ & & \\
\hline
\end{tabular}

كما تظهر النتائج ضرورة عقد برامج تدريبية فيما يخص معايير الجودة والاعتماد الأكاديمي إذ أظهرت النتائج أن غالبية أعضاء الهيئة التدريسية

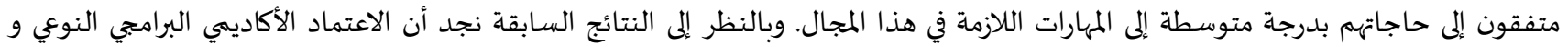

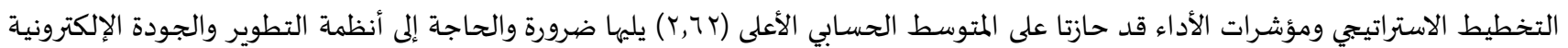
وإدارة ضمان الجودة ومن ثم الحاجة إلى الاعتمادات الاكاديمية البرامجية الدولية. يبين الجدول (11) يبين نتائج التحليل الوصفي لاحتياجات أعضاء التدريس وفقا للمجالات التعليمية: 
جدول(11): يبين نتائج التحليل الوصفي لاحتياجات أعضياء التدريس وفقاً للمجالات التعليمية

\begin{tabular}{|c|c|c|c|c|c|c|}
\hline \multirow[t]{2}{*}{ المتوسط } & \multicolumn{3}{|c|}{ درجة الحاجة } & & \multirow[t]{2}{*}{ الحاجة التدريبية } & \multirow{24}{*}{ التعليمية المارات } \\
\hline & عالية & متوسطة & منخفضة & & & \\
\hline \multirow[b]{2}{*}{ r.VI } & $0 \leqslant 0$ & NT & $r \Lambda$ & ك & \multirow[t]{2}{*}{ أساليب التدريس الحديثة } & \\
\hline & $1 ., 0$ & $1 T, r$ & 0,7 & $\%$ & & \\
\hline \multirow[b]{2}{*}{$r, 70$} & $\varepsilon \vee \wedge$ & $1 \leqslant 1$ & $\varepsilon V$ & ك & \multirow{2}{*}{ تخطيط وتصيميم التدريس وفقاً لمعايير } & \\
\hline & $v \cdot, 7$ & $r \cdot, \Lambda$ & 7,9 & $\%$ & & \\
\hline \multirow[b]{2}{*}{$r, 71$} & $\varepsilon \varepsilon$. & 191 & ro & ك & \multirow{2}{*}{ كتابة تقرير المقرر وفقاً لمعايير الجودة } & \\
\hline & 70, & $r \Lambda, Y$ & $0, r$ & $\%$ & & \\
\hline \multirow[b]{2}{*}{ r,Tt } & $\{7\}$ & 17. & 纟o & ك & \multirow{2}{*}{ توصيف المقرر(Syllabus) وفقاً لمعايير } & \\
\hline & 71,1 & 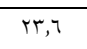 & 7,7 & $\%$ & & \\
\hline \multirow[b]{2}{*}{ r,ON } & $\varepsilon r \varepsilon$ & T.7 & $r 7$ & ك & \multirow[b]{2}{*}{ صياغة نواتج التعليم } & \\
\hline & $7 r, 7$ & $r \cdot, \varepsilon$ & $0, r$ & $\%$ & & \\
\hline \multirow[b]{2}{*}{ r,TV } & $\varepsilon \vee \varepsilon$ & 174 & rq & ك & \multirow[t]{2}{*}{ دمج مهارات التفكير أثناء بناء المقرر الدراسي } & \\
\hline & 1. & $r \varepsilon, 1$ & $\varepsilon, r$ & $\%$ & & \\
\hline \multirow[b]{2}{*}{$r, T \Lambda$} & $\varepsilon V Y$ & IVA & 17 & ك & \multirow[t]{2}{*}{ توجيه الطلاب نحو التعلم الذاتي } & \\
\hline & 79,18 & $r 7, r$ & $r, \varepsilon$ & $\%$ & & \\
\hline \multirow[b]{2}{*}{ المتوسط } & \multicolumn{3}{|c|}{ 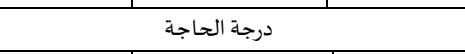 } & & \multirow[t]{2}{*}{ الحاجة التدريبية } & \\
\hline & عالية - ع الية & متوسطة & منخفضية & & & \\
\hline \multirow[b]{2}{*}{$r, 7$} & $\varepsilon r \eta$ & 194 & ऍ & ك & \multirow[t]{2}{*}{ صياغة أسئلة الاختبارات الموضيوعية } & \\
\hline & $7 \varepsilon, \varepsilon$ & $r \Lambda, \varepsilon$ & 0,7 & $\%$ & & \\
\hline \multirow[b]{2}{*}{ r,OY } & rar & TTV & $\varepsilon V$ & ك & \multirow{2}{*}{ الاستقصياء العلمي من خلال صياغة الأسئلة } & \\
\hline & ov,q & rr,o & 7,9 & $\%$ & & \\
\hline \multirow[b]{2}{*}{$r, T V$} & $\varepsilon \wedge 1$ & $1 \leqslant 9$ & $r 7$ & ك & \multirow{2}{*}{ تحليل نتائج الاختبارات والاستفادة منها في } & \\
\hline & VI & rr & $0, r$ & $\%$ & & \\
\hline
\end{tabular}

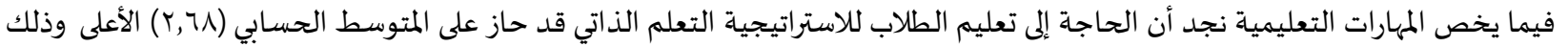
في ضوء التغييرات الحالية التي تستدعي اعتماد وانفتاح الطالب على مصادر التعليم المختلفة يكل يسر وسهولة. وتلتها الحاجة إلى أساليب التدريس الحديثة التي تتناسب مع التطورات التكنولوجية وخاصة ظهور مفهوم التعلم عن بعد وتلتها الحاجة إلى تحليل نتائج الاختبارات والاستفادة منها في تطوير المقرر لمعرفة نقاط القوة والضعف بالإضافة إلى دمج مهارات التفكير أثناء بناء المقرر الدراسي. كما أظهرت النتائج ضرورة الحاجة إلى تخطيط وتصيميم التدريس وفقاً لمعايير الجودة. وفي الجدول (r ا) الاتي تظهر نتائج الاحتياجات التدريبية لأعضاء التدريسية المختصة في المجالات التقنية والقيادية:

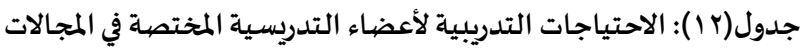

\begin{tabular}{|c|c|c|c|c|c|c|}
\hline \multirow[t]{2}{*}{ المتوسط } & \multicolumn{3}{|c|}{ درجة الحاجة } & & \multirow[t]{2}{*}{ الحاجة التدرببية } & \multirow{20}{*}{ 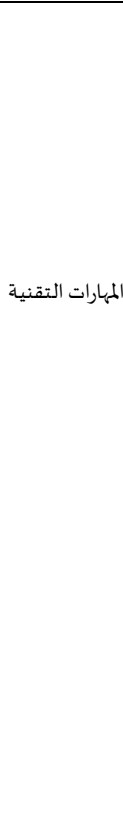 } \\
\hline & عالية & متوسطة & منخفضة & & & \\
\hline \multirow[t]{2}{*}{$r, 7$} & $\varepsilon r$ & 191 & $\varepsilon$ & ك & \multirow[t]{2}{*}{ تطبيقات الذكاء الصناعي في التعليم } & \\
\hline & $7 r, 0$ & $\lceil\curlywedge, \varepsilon$ & 7,1 & $\%$ & & \\
\hline \multirow[t]{2}{*}{$r, \varepsilon$} & $r r_{\Lambda}$ & $r \varepsilon 1$ & $\mathrm{vv}$ & ك & \multirow[t]{2}{*}{ تطبيقات الذكاء الصناعي في الصحة } & \\
\hline & $\varepsilon 9,9$ & ro,7 & $11, \varepsilon$ & $\%$ & & \\
\hline \multirow[t]{2}{*}{$r, 7$} & 纟At & $1 \leqslant 9$ & ro & ك & \multirow[t]{2}{*}{ تطبيقات الأجهزة الذكية في تجويد العملية التعليمية } & \\
\hline & $v, r$ & rt & $r, v$ & $\%$ & & \\
\hline \multirow[t]{2}{*}{$r, 0$} & rur & YIE & 09 & ك & \multirow[t]{2}{*}{ تصميم الأنفوجر افيك التعليمي الثابت (صورة } & \\
\hline & 07,7 & $r 1,7$ & $\Lambda, V$ & $\%$ & & \\
\hline \multirow[t]{2}{*}{ r,Or } & $r \Lambda \nu$ & $r \cdot \Lambda$ & 71 & ك & \multirow[t]{2}{*}{ تصميم الأنفوجر افيك المتحرك (فيديو) } & \\
\hline & $O V, r$ & $r ., v$ & 9 & $\%$ & & \\
\hline \multirow[t]{2}{*}{$r, 7 \varepsilon$} & $\varepsilon 77$ & $1 \leqslant 7$ & $\varepsilon \varepsilon$ & ك & \multirow[t]{2}{*}{ توظيف إنترنت الأشياء في العملية التعليمية } & \\
\hline & $7 \Lambda, \Lambda$ & $r, T$ & 7,0 & $\%$ & & \\
\hline \multirow[b]{2}{*}{$r, 00$} & £01 & 107 & $\varepsilon 9$ & ك & \multirow[b]{2}{*}{ هندسة برمجيات التعليم "التعلمالذكي" } & \\
\hline & 77,7 & $r$ & $V, r$ & $\%$ & & \\
\hline \multirow[t]{2}{*}{ المتوسط } & & 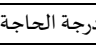 & & & \multirow[t]{2}{*}{ الحاجة التدريبية } & \\
\hline & عالية & متوسطة & منخفضية & & & \\
\hline \multirow[b]{2}{*}{$r, \varepsilon q$} & $\varepsilon r$. & 187 & 7. & ك & \multirow[b]{2}{*}{ مهارات إدارة الوقت واستثماره } & \\
\hline & $7 \pi$ & rq & 1,9 & $\%$ & & \\
\hline
\end{tabular}




\begin{tabular}{|c|c|c|c|c|c|c|}
\hline \multirow[b]{2}{*}{$r, 0 \Lambda$} & $\varepsilon r \eta$ & 178 & or & ك & \multirow[b]{2}{*}{ مهارات الاتصـال الفعال } & \multirow{16}{*}{ 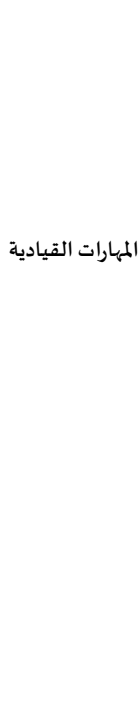 } \\
\hline & $7 \varepsilon, \varepsilon$ & $r \varepsilon, V$ & $\mathrm{~V}, \Lambda$ & $\%$ & & \\
\hline \multirow[b]{2}{*}{$r, 70$} & $\varepsilon 7 V$ & $1 \leqslant 9$ & $\varepsilon$. & ك & \multirow[b]{2}{*}{ مهارات التفكير الإبداعي } & \\
\hline & 79 & rr & 0,9 & $\%$ & & \\
\hline \multirow[b]{2}{*}{$r, 0 \Lambda$} & 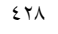 & 111 & $\varepsilon V$ & ك & \multirow[b]{2}{*}{ مهارة إدارة العلاقات } & \\
\hline & $7 r, Y$ & $r 7, \mathrm{~V}$ & 7,9 & $\%$ & & \\
\hline \multirow[t]{2}{*}{ T,OV } & $\varepsilon r r$ & int & 01 & ك & \multirow[t]{2}{*}{ إدارة الصراعات والأزمات } & \\
\hline & $\pi r, r$ & TV & $\mathrm{v}, 0$ & $\%$ & & \\
\hline \multirow[b]{2}{*}{ T,07 } & $\varepsilon 1 \Lambda$ & 117 & or & ك & \multirow[t]{2}{*}{ إدارة الاجتماعات } & \\
\hline & $71, \mathrm{~V}$ & $T V, 0$ & $\mathrm{v}, \mathrm{v}$ & $\%$ & & \\
\hline \multirow[b]{2}{*}{$r, 01$} & rov & rm & $\varepsilon r$ & ك & \multirow[t]{2}{*}{ استر اتيجيات التفاوض } & \\
\hline & $00, \mathrm{~V}$ & $r v, q$ & $7, \varepsilon$ & $\%$ & & \\
\hline \multirow[b]{2}{*}{$r, 70$} & $\sum 7 t$ & 101 & $r 7$ & ك & \multirow[t]{2}{*}{ الإبداع في صناعة المبادرات في البيئة الأكاديمية } & \\
\hline & 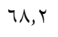 & $r, r$ & $0, r$ & $\%$ & & \\
\hline \multirow[b]{2}{*}{$r, 7$} & $\varepsilon r$. & 111 & ru & ك & \multirow[t]{2}{*}{ الإبداع في صناعة المبادرات المجتمعية } & \\
\hline & Tr,o & $r 7, V$ & 0,7 & $\%$ & & \\
\hline
\end{tabular}

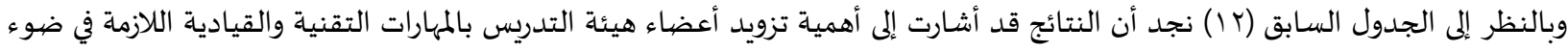

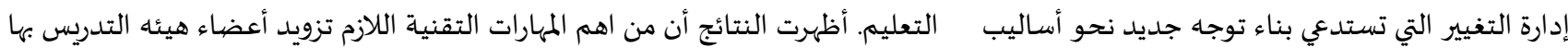

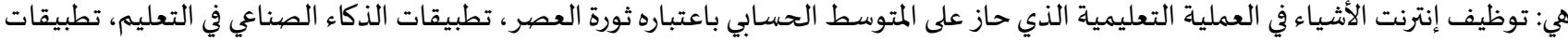
الأجهزة الذكية في تجويد العملية التعليمية وتصميم الانفوجرافيك المتحرك (فيديو) وتصميم الانفوجرافيك التعليمي الثابت (صورة).

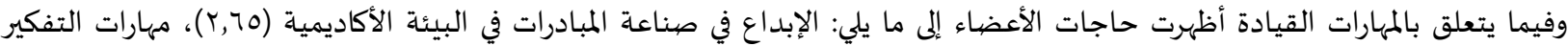

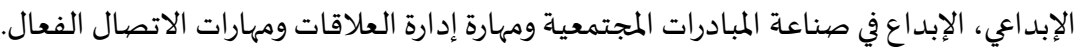

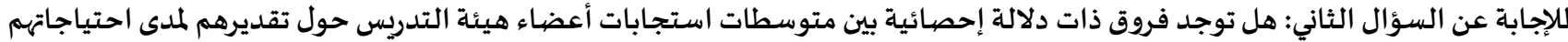

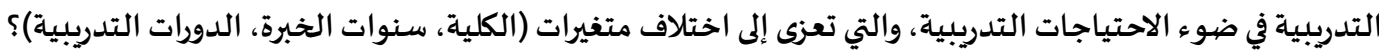

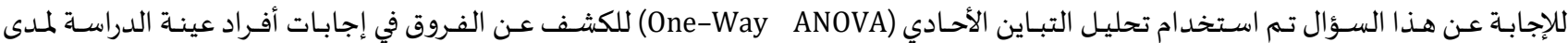

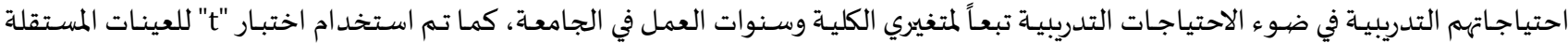
للكشف عن الفروق في استجابات أفراد عينة الدراسة احتياجاتهم التدريبية في ضوء الاحتياجات التدرببية تبعاً (Independent - Sample T. Test) لمتغير الدورات التدريبية, والجداول أدناه توضح ذلك:

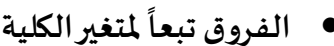
جدول (rا): نتائج تحليل التباين (One- Way ANOVA) للكشف عن الفروق في استجابات أفراد عينة الدراسة لمدى احتياجاتهم التدريبية في ضوء

الاحتياجات التدرببية تبعاً لمتغير الكلية الكئية

\begin{tabular}{|c|c|c|c|c|c|c|}
\hline الدلالة الإحصائية & " قيمة "f" & الانحراف المعياري & المتوسط الحسابي & 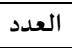 & الكلية & \\
\hline \multirow[t]{16}{*}{$\cdot, \ldots$} & \multirow[t]{16}{*}{$0,70 \varepsilon$} & ., TVVE. & $r, V \cdot I r$ & ry & كلية المجتمع & \multirow[t]{16}{*}{ الاحتياجات التدريبية } \\
\hline & & . Кг人१А & r, rOYI & $r \varepsilon$ & كلية الهندسة & \\
\hline & &.,$T 1170$ & $r, V \varepsilon r I$ & 09 & الكلية الجامعية بمحافظة حقل & \\
\hline & & . rq97ז & $r, 090$. & $9 \varepsilon$ & كلية العلوم & \\
\hline & & ., rY. $\varepsilon q$ & $r, \Sigma q \vee 7$ & 71 & الكلية الجامعية بمحافظة الوجه & \\
\hline & & $\cdot$, rMAYA & $r,\{019$ & $\Lambda V$ & كلية التربية والآداب & \\
\hline & &.,$\Gamma 0190$ & $r, \& 191$ & or & كلية الشريعة والأنظمة & \\
\hline & & $\cdot, \pi \cdot 10$ & r, TATr & r) & كلية الصيدلة & \\
\hline & & . TrITr & r,TV10 & $\varepsilon \wedge$ & الكلية الجامعية بمحافظة تيماء & \\
\hline & & $\cdot, r \cdot r q 1$ & $r, 0711$ & 0. & الكلية الجامعية بمحافظة املج & \\
\hline & &., Ү人५.० & r,Yoor & iV & كلية الفنون والتصاميم (الاقتصاد المنزلي) & \\
\hline & & . rV Y & $r, 0799$ & $r \varepsilon$ & كلية الحاسبات وتقنية المعلومات & \\
\hline & & . Y\&AYT & $r, 71 \wedge 7$ & rq & كلية إدارة الأعمال & \\
\hline & &., $49.9 r$ & $r, 01 \cdot r$ & rI & كلية العلوم الطبية التطبيقية & \\
\hline & &.,$\Gamma 1077$ & $r, 0979$ & ru & كلية الطب & \\
\hline & &., $19 r T V$ & $r, 0 . \varepsilon_{0}$ & $\Lambda$ & الكلية الجامعية بمحافظة بضباء & \\
\hline
\end{tabular}




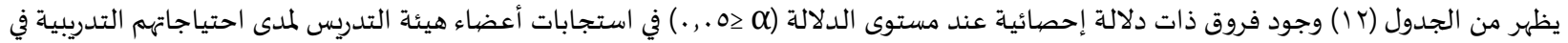

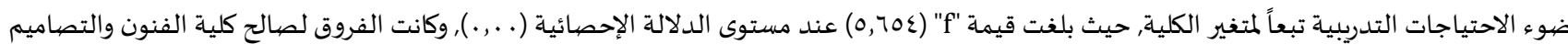

(الاقتصاد المنزلي) حيث بلغ المتوسط الحسابي (Y,VY). ولمعرفة مواقع الفروق في الاحتياجات التدريبية تبعاً لمتغير الكلية تم تطبيق اختبار شيفيه (Scheffe)

للمقارنات البعدية.

جدول(ع (): نتائج تطبيق اختبار (Scheffe) للكشف عن الفروق في الاحتياجات التدربيية تبعاً لمتغير الكلية

\begin{tabular}{|c|c|c|c|c|c|c|c|c|c|c|c|c|c|c|c|c|c|}
\hline 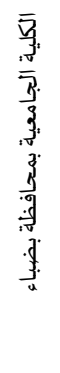 & $\begin{array}{l}\frac{y}{3} \\
\overline{7} \\
\overline{3}\end{array}$ & 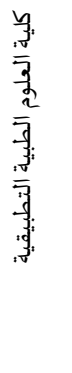 & 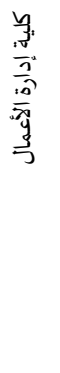 & 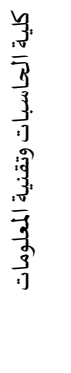 & 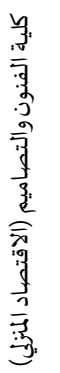 & 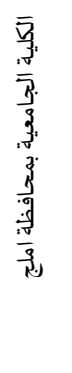 & 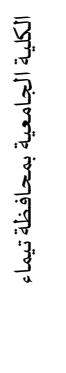 & 尝. & 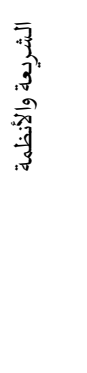 & 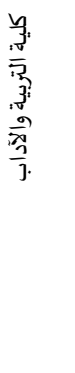 & 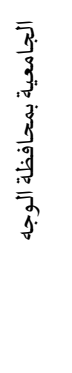 & $\frac{3}{2}$ & 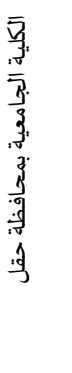 & $\overline{5}$ & $\overline{3}$ & $\begin{array}{l}\bar{y} \\
3 \\
\frac{1}{9} \\
\overline{3} \\
\frac{3}{3}\end{array}$ & 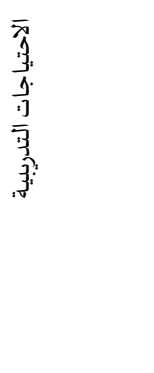 \\
\hline & & & & & & & & & & & & & & & & $r, V$. & كلية المجتمع \\
\hline & & & & & & & & & & & & & & & $*_{.}^{*}, \leqslant 0$ & r, ro & كلية الهندسة \\
\hline & & & & & & & & & & & & & & $*_{.,}^{*} \leqslant 9$ & ., . \&- & $r, V \varepsilon$ & بمحافظة حقل \\
\hline & & & & & & & & & & & & &., 10 & . &., 11 & $r, 09$ & كلية العلوم \\
\hline & & & & & & & & & & & &., 1 . & . ro & . YO- &.,$r$. & $r, 0$. & بمحافظة الوجهية \\
\hline & & & & & & & & & & &.,.$\varepsilon$ &., $1 \varepsilon$ &., $\mathrm{TA}$ &.,$Y ו-$ &.,$Y \varepsilon$ & $r, \Sigma 7$ & ولية التربية \\
\hline & & & & & & & & & &.,.$\varepsilon$ &.,.$\wedge$ &., 11 & .,TY- &., $\mid V-$ &.,$Y \Lambda$ & $T, \sum Y$ & كلية الشربعة \\
\hline & & & & & & & & & . Y Y & .,Y.- &., $1 \mathrm{~V}$ &.,$. V-$ &., .1 & *.,\&।- &.,.$\varepsilon$ & $r, 77$ & كلية الصيدلة \\
\hline & & & & & & & &., $.1-$ & ., ro- & .,Yו- &., $1 V-$ &.,$\wedge-$ &.,$. V-$ & $*_{., \ell}^{*}$ &.,.$r$ & $r, T V$ & بمحافظة تيماء الكلية الجامعية \\
\hline & & & & & & &., 1 . &., 1 & ., $1 \varepsilon-$ & ., 1.- &., $.7-$ &.,.$r$ &., 11 &., $1 T-$ & . & $r, 07$ & بمحافظة املجية الجامعية \\
\hline & & & & & &., 19 &,$\ldots \lambda-$ & ., 1.- & $*_{.}^{*}, \Gamma \varepsilon-$ & . & . &., $17-$ &., $.1-$ & .,०.- &., $.0-$ & $r, V 7$ & كالتية الفنون \\
\hline & & & & &., 19 & .,..1- &., 1 . &., .9 &., 10 &., $11-$ & .,.v- &.,.$r$ &.,$I V$ & $*^{*}, r Y-$ & ., & $\mathrm{r}, \mathrm{OV}$ & كلية الحاسبات \\
\hline & & & &., $.0-$ &., $1 \varepsilon$ & .,. . 7- &., .0 &., .0 &.,$Y .-$ &., $17-$ &., $1 Y$ &.,$. Y-$ &., $1 Y$ &.,$r V-$ &., .1 & $T, T r$ & كلية إدارة \\
\hline & & &., 11 &., .7 & . ro &., .0 &., 17 &., 10 & .,. १- & .,. o- & .,..1- &., .9 & r & . &., 19 & $r, 01$ & الطلية العلوم \\
\hline & &., $.9-$ & .,.Y &.,$. r-$ &., 17 & .,. $\varepsilon-$ &., .1 &.,.$V$ &., $11-$ &., $1 \leq-$ & ., 1.- &., $.1-$ &., 10 & . ro- &., 1. & $r, 7$. & كلية الطب \\
\hline & .9. &., .1 &., 11 &.,.$V$ & . ro &., .7 &., $1 \mathrm{~V}$ &., 17 &., $.9-$ &., $.0-$ &., $.1-$ &., .9 & . $T \varepsilon$ & . YO- & ., r. & r,o. & بمحافظة بضباء الجامعية \\
\hline
\end{tabular}

*الفروق دالة إحصائيا عند مستوى الدلالة (م) م . , ) )

يظهر من الجدول (ع ا) أن مواقع الفروق في الاحتياجات التدريبية تبعاً لمتغير الكلية كانت بين الكليات (الهندسة) و ( المجتمع) وكانت لصالح كلية المجتمع حيث بلغ المتوسط الحسابي لكلية المجتمع (r,V. بينما بلغ المتوسط الحسابي لكلية الهندسة (Y,Y,)، وبين الكليات (الهندسة) و ( العلوم)

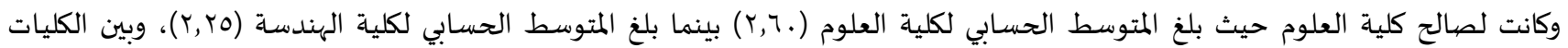


(الهندسة) و (الكلية الجامعية بمحافظة تيماء) وكانت لصالح الكلية الجامعية بمحافظة تيماء حيث بلغ المتوسط الحسابي للكلية الجامعية بمحافظة

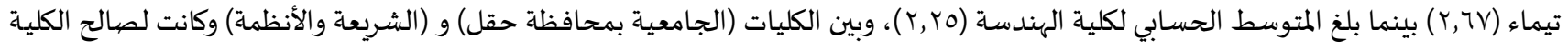
الجامعية بمحافظة حقل حيث بلغ المتوسط الحسابي للكلية الجامعية بمحافظة حقل (Y,V ) بينما بلغ المتوسط الحسابي لكلية الشريعة والأنظمة

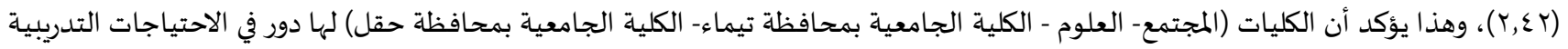
لدى أعضاء هيئة التدريس المنتسبين لها بالمقارنة مع الكليات الأخرى والتي لم تظهر فروق دالة إنهات إحصائياً عند المقارنة فيما بينها.

• •

جدول(0) ): نتائج تحليل التباين (One- Way ANOVA) للكشف عن الفروق في استجابات أفراد عينة الدراسة للاحتياجات التدريبية تبعاً لمتغير

سنوات الخبرة

\begin{tabular}{|c|c|c|c|c|c|c|}
\hline الدلالة الإحصائية & قيمة "f" & الانحراف المعياري & المتوسط الحسابي & العدد & السنوات & \\
\hline \multirow[t]{3}{*}{$\cdot, \cdot \wedge \varepsilon$} & \multirow[t]{3}{*}{$r,\{\wedge \uparrow$} & TrAlN. & r,ov91 & $\varepsilon V$. & اقل من ه سنوات & \multirow[t]{3}{*}{ الاحتياجات التدريبية } \\
\hline & & rvilt. & r,01TA & 189 & من ه-. اسنوات & \\
\hline & & $0 . .1$. & r,OYI. & $r \Lambda$ & أكبر من · ا سنوات & \\
\hline
\end{tabular}

يوضح الجدول (10) عدم وجود فروق ذات دلالة إحصائية عند مستوى الدلالة (0> ه ...) في استجابات أفراد عينة الدراسة للاحتياجات

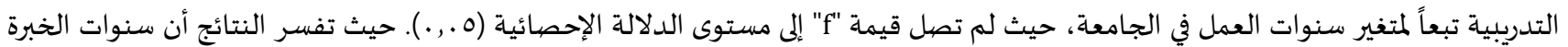

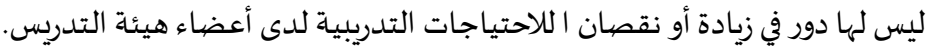

جدول(I 7 ): نتائج (Independent - Sample T. Test) للكشف عن الفروق في إجابات أفراد عينة الدراسة للاحتياجات التدريبية تُعزى لمتغير الدورات التدريبية

\begin{tabular}{|c|c|c|c|c|c|c|c|}
\hline الدلالة الإحصائية & درجات الحرية & "قيمة"t" & الانحراف المعياري & المتوسط الحسابي & العدد & الدورات & \\
\hline \multirow[t]{2}{*}{,$\ldots \wedge$} & TVO & $r, T V$. & $r \varepsilon r \mid \varepsilon$. & r,0V97 & or. & نعم & الاحتياجات التدربية \\
\hline & & & $r q \mid \leqslant \wedge$. & $r, \Sigma 9 r_{0}$ & $10 \mathrm{~V}$ & $\gamma$ & \\
\hline
\end{tabular}

يظهر من الجـدول رقـم (7 ا ) وجـود الفروق في إجابـات أفراد عينـة الدراسـة للاحتياجـات التدريبية تُعزى لمتغيز الدورات التدرببية، حيـث بلغت

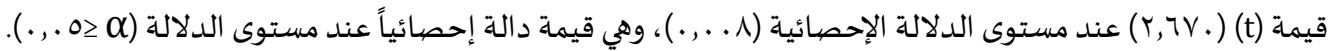

مناقشة النتائج: أظهرت النتائج وجود فروق ذات دلالة إحصائية بين متوسطات استجابات أعضاء هيئة التدريس حول تقديرهم لمدى احتياجاتهم التدربيية في ضوء الاحتياجات التدريبية، والتي تعزى إلى اختلاف متغير الكلية،وهذذا يدل على دور للكلية في حاجة أعضاء هيئة التدريس إلى مهارات شخصياة

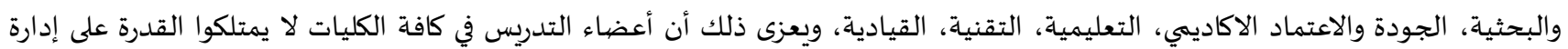

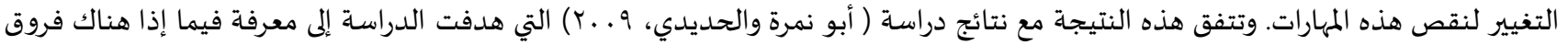

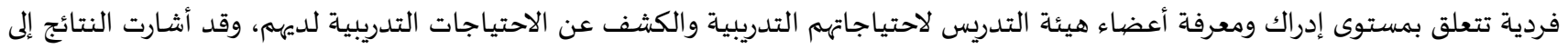
وجود فروق بين أعضاء الهيئة التدريسية بمستوى تقديرهم لحاجتهم التدريبية إلى التخطيط وإدارة قاعة التدريس تعزى إلى الرتبة الأكاديمية .

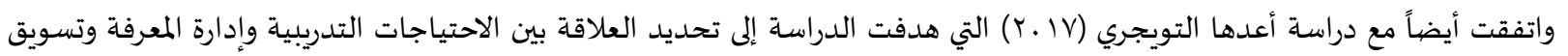
جودة الخدمة التعليمياة، أشارت النتائج إلى أن إدارة المعرفة تتوفر بنسب قليلة، اعتماد نجاح البرامج التدريبية على نجاح عملية التخطيط لعملية

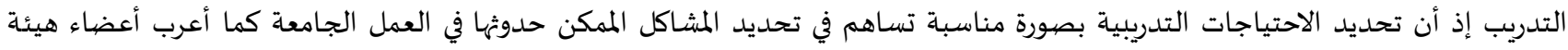

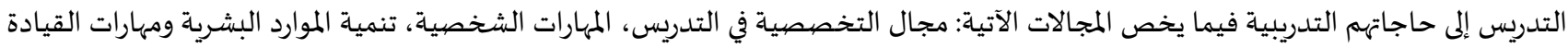

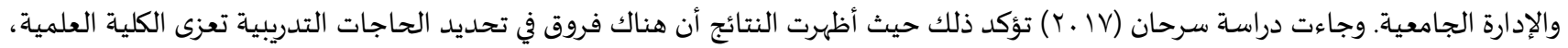

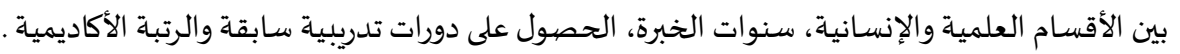
كما أظهرت النتائج وجود فروق ذات دلالة إحصائية بين متوسطات استجابات أعضاء هيئة التدريس حول تقديرهم لمدى احتياجاتهم

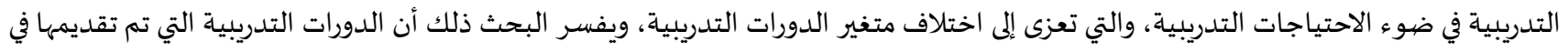

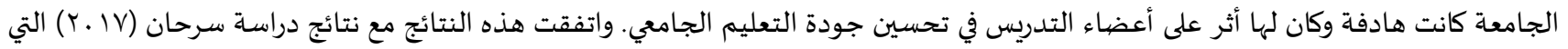


هدفت إلى تحديد حاجات أعضاء التدريس للبرامج التجريبية ومعرفة فيما اذا هناك تأثير لمتغيرات الجنس، الخبرة, وأظهرت النتائج أن هناك فروق في

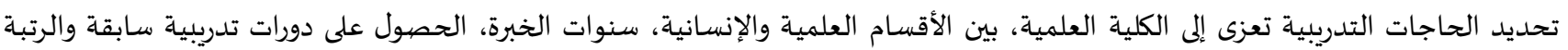

كما اتفقت مع دراسـة حرب (1) • (Y) التي هدفت الدراسة إلى تحديد احتياجات هيئة التدريس إلى المهارات التقنية. أظهرت نتائج التحليل

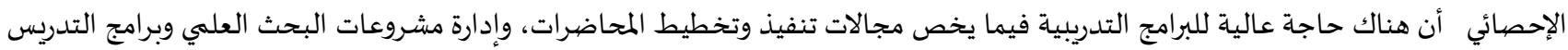

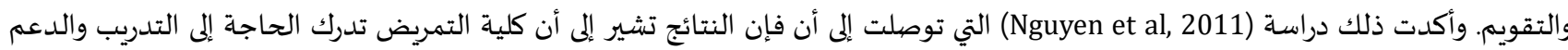
لاستخدام التقنيات التعليمية بفعالية وكفاءة.

وختاماً ومن هنا يمكن القول إن أعضياء هيئة التدريس قد اتفقوا على أهمية الاحتياجات التدريبية بما يعزز جودة التعليم الجامعي في المجالات

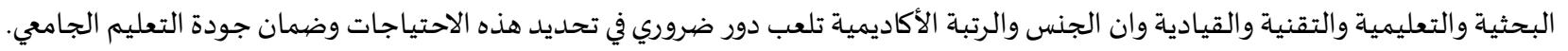

المقترحات والتوصيات:

أشارت نتائج الدراسة إلى أهمية عقد البرامج التدريبية لأعضاء هيئة التدريس في جامعة تبوك بمختلف التخصصيات والرتب الأكاديمية بما يعزز ضمان جودة التعليم الجامعي وقد أظهرت الدراسة إلى الحاجة لعقد البرامج التدريبية فيما يتعلق بجميع المهارات التالية تطوير الذات والتعليمية والتقنية

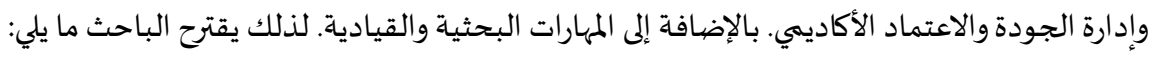
l. . عقد برامج تدريبية تختص باستراتيجيات الإقناع والتأثير وبناء فريق العمل.

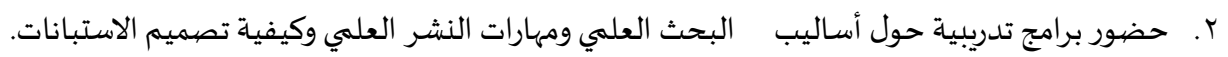

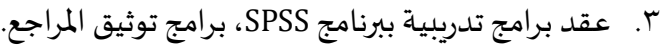

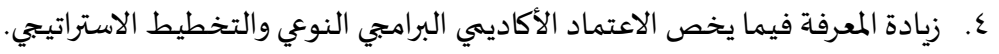

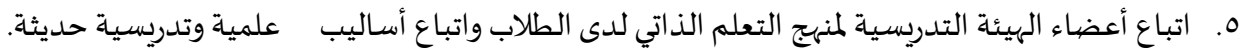

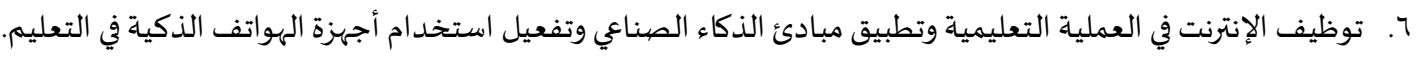

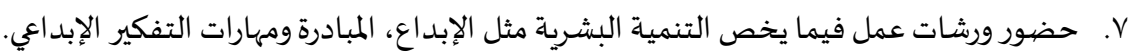

المراجح:

أولاً: المراجع العربية: أمراج:

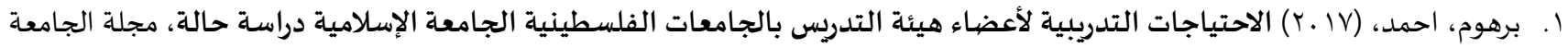

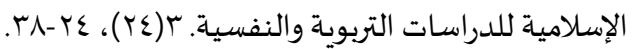

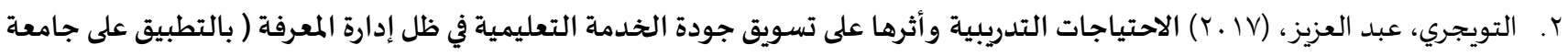

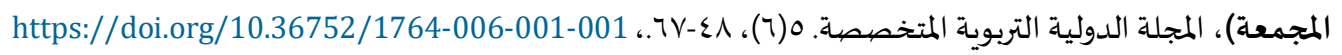

r. حبيب، صفاء وحسين، شيماء، (7) (Y) تطوير كفايات أداء أعضاء هيئة التدريس الجامعي وانعكاساتها على تحقيق الجودة الشـاملة في

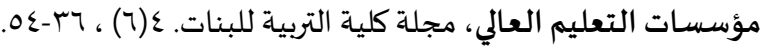

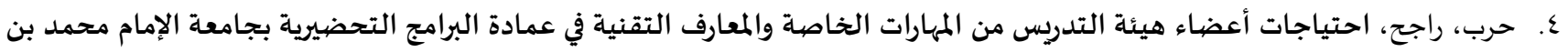
سعود الإسلامية في ضوء معايير الجودة الأكاديمية (دراسة استباقية لوضع برنامج تدريبي مبني على الاحتياجات)، المجلة الدولية التربوية

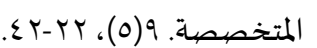

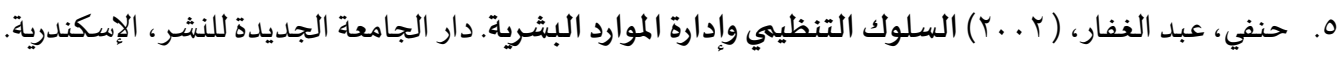

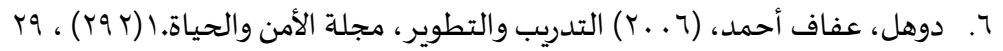

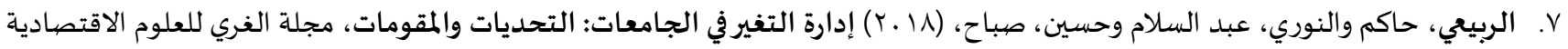

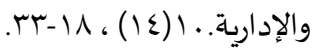

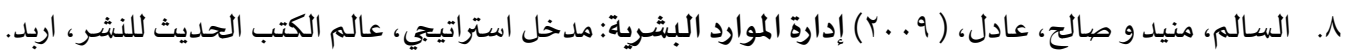

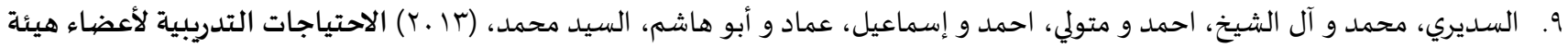

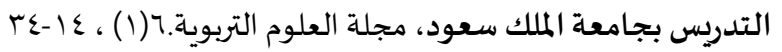
• ا. سرحان، محمد، (V) ـ إ) تحديد الحاجات التدريبية لأعضاء هيئة التدريس بجامعة البلقاء التطبيقية في مجالات تكنولوجيا التعليم، مجلة

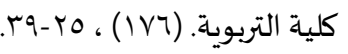




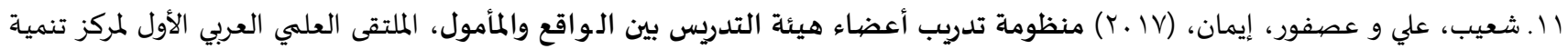
قدرات أعضياء هيئة التدريس بـجامعة بنها.

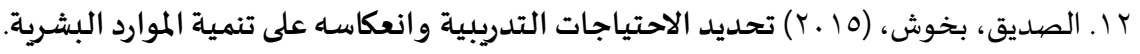
با ـ الطعاني، أحمد، ( ج . . r) التدريب الإداري المعاصر،، عمان: دار المسيرة.

ع ا. عشيبة، فتحي دروشي، ( . . ا) الجودة الشاملة وإمكانيات تطبيقها في التعليم الجامعي المصري - دراسـة تحليليةفي: تطوير نظم إعداد المعلم

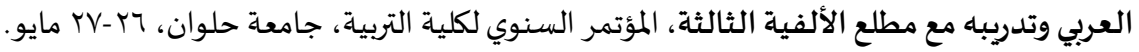
ا . العقيلي، عمر وصفي، (9 . . ب) مدخل إلى المنتهجية المتكاملة لإدارة الجودة الشـاملة، عمان: دار وائل للنشر ا ـ العميان، محمود، ( ( . . السلوك التنظيهي في منظمات الأعمال، بيروت: دار وائل للنشر. V ا . العواودة، وليد، (I ا ـ أثراستخدام إستراتيجية التدريب على أداء العاملين لدى الدوائر الإدارية في جـامعة آل البيت، مجلة المنارة للبحوث،

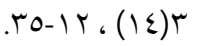

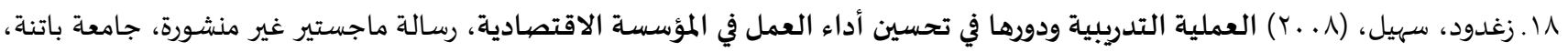
الجزائر.

19. فالح، محمد، (ع . . r) إدارة الموارد البشرية، عرض وتحليل، القاهرة: دار الحامد للنشر والتوزيع • . . سليم، عادل، ( ع . . ) تحليل وتقييم فاعلية البرامج التدريبية أثناء العمل وتأثيرها على أداء العاملين وسلوكهم شركة رأس النوف لتصنيع النفط والغازفي الجماهيرية الليبية، رسالة ماجستير غير منشورة، جامعة آل البيت، الأردن. ا ا. الكفافي، محمد، (V . . r) الاستثمارفي الموارد البشرية للمنافسة العالمية، بيروت: الدار الثقافية. r r. نجيب، سبع، (V) أثر التدريب في تحسين أداء العاملين بالمؤسسة الاقتصادية "دراسة ميدانية بالشركة الوطنية للكهرباء والغاز، رسالة ماجستير غير منشورة، جامعة محممد خضير، الجزائر.

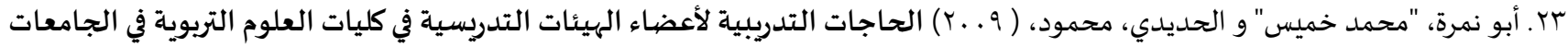

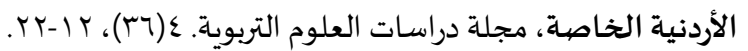

ثانيا: المراجع الأجنبية:

[1] Abouelenein. Y. A. M., Training Needs for Faculty Members: Towards Achieving Quality of University Education in the Light of Technological Innovations, Educational Research and Reviews, 11(13) (2016), 1180-1193, https://doi.org/10.5897/err2015.2377

[2] Díaz. M. J. F., Santaolalla. R. C., \& González. A. G., Faculty attitudes and training needs to respond the new European Higher Education challenges, Higher Education, 60(1) (2010), 101-118, https://doi.org/10.1007/s10734009-9282-1

[3] Nasreen. A., \& Mirza. M., Faculty training and development in the public sector universities of Punjab, International Journal of Business and Social Science, 3(3) (2012), 229-241

[4] Nguyen. D. N., Zierler. B., \& Nguyen. H. Q., A survey of nursing faculty needs for training in use of new technologies for education and practice, Journal of Nursing Education, 50(4) (2011), 181-189, https://doi.org/10.3928/01484834-20101130-06 


$$
\text { المجلة الدولية للدراسـات التربوية والنفسية }
$$

International Journal of Educational \& Psychological Studies (EPS)

Journal Homepage: https://www.refaad.com/views/EPSR/Home.aspx

www.refaad.com

ISSN: 2520-4149 (Online) 2520-4130 (Print)

\title{
Training Needs of Faculty Members at The University of Tabuk in Light of The Higher Education Quality Requirements
}

\author{
Mohammed A. Alasmrai \\ Assistant Professor of Planning Continuing Programs, University of Tabuk, KSA \\ Malasmrai@ut.edu.sa
}

Received Date : $16 / 11 / 2019$

Accepted Date : 17/12/2019

DOI : https://doi.org/DOI:10.31559/EPS2020.7.3.4

\begin{abstract}
This study aimed to identify the training needs of faculty members at the University of Tabuk in the light of the requirements of quality of Higher Education. The study sample included 677 teaching staff. The questionnaire included training needs related to the following skills: personal, educational, technical, leadership, quality management, academic accreditation and research. The statistical analysis program (SPSS) was used and iterations, percentages, arithmetic averages and test were used. The results showed that all faculty members are interested and need all training programs related to the skills mentioned and the most important needs are the need for scientific research methods. The results also indicate that there are differences and differences in determining these needs due to the variables of gender, academic rank and previous courses. This study recommended the importance of holding training programs in the fields of scientific research and communication skills and follow the curriculum of self-education for students.
\end{abstract}

\section{Keywords: Training Needs; Faculty Members; Higher Education Quality; University of Tabuk.}

\section{References:}

[1] Al'ewawdh. Wlyd, Athr Astkhdam Estratyjyh Altdryb 'la Ada' Al'amlyn Lda Aldwa'r Aledaryh Fy Jam't Al Albyt, Mjlt Almnarh Llbhwth, 3(14) (2011), 12-35.

[2] Al'myan, Mhmwd, Alslwk Altnzymy Fy Mnzmat Ala'mal, Byrwt: Dar Wa'l Llnshr, (2001).

[3] Al'qyly. 'mr Wsfy, Mdkhl Ela Almnthjyh Almtkamlh Ledart Aljwdh Alshamlh, 'man: Dar Wa'l Llnshr, (2009).

[4] 'shybh Fthy Drwysh, Aljwdh Alshamlh Wemkanyat Ttbyqha Fy Alt'lym Aljam'y Almsry- Drash Thlylyhfy: Ttwyr Nzm 'edad Alm'lm Al'rby Wtdrybh M' Mtl' Alalfyh Althalthh, Alm'tmr Alsnwy Lklyt Altrbyh, Jam't Hlwan, 26-27 Mayw, (2000).

[5] Abouelenein. Y. A. M., Training Needs for Faculty Members: Towards Achieving Quality of University Education in the Light of Technological Innovations, Educational Research and Reviews, 11(13) (2016), 1180-1193, https://doi.org/10.5897/err2015.2377

[6] Brhwm. Ahmd, Alahtyajat Altdrybyh La'da' Hy't Altdrys Baljam'at Alflstynyh Aljam'h Aleslamyh Drast Halh, Mjlt Aljam'h Aleslamyh Lldrasat Altrbwyh Walnfsyh. 3(24) (2017), 24-38.

[7] Díaz. M. J. F., Santaolalla. R. C., \& González. A. G., Faculty attitudes and training needs to respond the new European Higher Education challenges, Higher Education, 60(1) (2010), 101-118, https://doi.org/10.1007/s10734. 009-9282-1

[8] Dwhl. 'faf Ahmd, Altdryb Walttwyr, Mjlt Alamn Walhyah, 1(292) (2006), 29.

[9] Falh. Mhmd, Edart Almward Albshryh, 'rd Wthlyl, Alqahrh: Dar Alhamd Llnshr Waltwzy', (2004).

[10] Hbyb. Sfa' \& Hsyn. Shyma', Ttwyr Kfayat Ada' A'da' Hy't Altdrys Aljam'y Wan'kasatha 'la Thqyq Aljwdh Alshamlh Fy M'ssat Alt'lym Al'aly, Mjlh Klyt Altrbyh Llbnat. 4(6) (2016), 36-54.

[11] Hnfy. 'bd Alghfar, Alslwk Altnzymy Wedart Almward Albshryh. Dar Aljam'h Aljdydh Llnshr, Aleskndryh, (2002). 
[12] Hrb. Rajh, Ahtyajat A'da' Hy't Altdrys Mn Almharat Alkhash Walm'arf Altqnyh Fy 'madt Albramj Althdyryh Bjam't Alemam Mhmd Bn S'wd Aleslamyh Fy Dw' M'ayyr Aljwdh Alakadymyh (Drash Astbaqyh Lwd' Brnamj Tdryby Mbny 'la Alahtyajat), Almjlh Aldwlyh Altrbwyh Almtkhssh. 9(5), 22-42.

[13] Alkfafy. Mhmd, Alastthmar Fy Almward Albshryh Llmnafsh Al'almyh, Byrwt: Aldar Althqafyh, (2007).

[14] Nasreen. A., \& Mirza. M., Faculty training and development in the public sector universities of Punjab, International Journal of Business and Social Science, 3(3) (2012), 229-241

[15] Nguyen. D. N., Zierler. B., \& Nguyen. H. Q., A survey of nursing faculty needs for training in use of new technologies for education and practice, Journal of Nursing Education, 50(4) (2011), 181-189, https://doi.org/10.3928/01484834-20101130-06

[16] Njyb. Sb', Athr Altdryb Fy Thsyn Ada' Al'amlyn Balm'ssh Alaqtsadyh "Drash Mydanyh Balshrkh Alwtnyh Llkhrba' Walghaz, Rsalt Majstyr Ghyr Mnshwrh, Jam't Mhmd Khdyr, Aljza'er, (2017).

[17] Abw Nmrh. "Mhmd Khmys" \& Alhdydy. Mhmwd, Alhajat Altdrybyh La'da' Alhy'at Altdrysyh Fy Klyat Al'lwm Altrbwyh Fy Aljam'at Alardnyh Alkhash, Mjlt Drasat Al'lwm Altrbwyh. 4(36) (2009), 12-22.

[18] Alrby'y. Hakm, Alnwry. 'bd Alslam \& Hsyn. Sbah, Edart Altghyr Fy Aljam'at: Althdyat Walmqwmat, Mjlt Alghry Ll'lwm Alaqtsadyh Waledaryh.10(14) (2018), 18-33.

[19] Alsalm. Mnyd \& Salh. 'adl, Edart Almward Albshryh: Mdkhl Astratyjy, 'alm Alktb Alhdyth Llnshr, Arbd, (2009)

[20] Alsdyq. Bkhwsh, Thdyd Alahtyajat Altdrybyh Wan'kash 'la Tnmyt Almward Albshryh, (2015).

[21] Alsdyry. Mhmd, Al Alshykh. Ahmd, Mtwly. Ahmd, Esma'yl. 'mad \& Abw Hashm. Alsyd Mhmd, Alahtyajat Altdrybyh La'da' Hy't Altdrys Bjam't Almlk S'wd, Mjlt Al'lwm Altrbwyh, 6(1) (2013), 14-34.

[22] Sh'yb. 'ly \& 'sfwr, Eyman, Mnzwmt Tdryb A'da' Hy't Altdrys Byn Alwaq' Walmamwl, Almltqa Al'Imy Al'rby Alawl Lmrkz Tnmyh Qdrat A'da' Hy't Altdrys Bjam't Bnha, (2017).

[23] Slym. 'adl, Thlyl Wtqyym Fa'lyt Albramj Altdrybyh Athna' Al'ml Wtathyrha 'la Ada' Al'amlyn Wslwkhm Shrkt Ras Alnwf Ltsny' Alnft Walghaz Fy Aljmahyryh Allybyh, Rsalt Majstyr Ghyr Mnshwrh, Jam't Al Albyt, Alardn, (2004).

[24] Srhan. Mhmd, Thdyd Alhajat Altdrybyh La'da' Hy't Altdrys Bjam't Alblqa' Alttbyqyh Fy Mjalat Tknwlwjya Alt'lym, Mjlt Klyt Altrbwyh. (176) (2017), 25-39.

[25] Alt'any.Ahmd, Altdryb Aledary Alm'asr, 'man: Dar Almsyrh, (2006).

[26] Altwyjry. 'bd Al'zyz, Alahtyajat Altdrybyh Wathrha 'la Tswyq Jwdh Alkhdmh Alt'lymyh Fy Zl Edarh Alm'rfh (Balttbyq 'la Jam't Almjm'h), Almjlh Aldwlyh Altrbwyh Almtkhssh. 5(6) (2017), 48-67., https://doi.org/10.36752/1764-006-001-001

[27] Zghdwd, Shyl, Al'mlyh Altdrybyh Wdwrha Fy Thsyn Ada' Al'ml Fy Alm'ssh Alaqtsadyh, Rsalt Majstyr Ghyr Mnshwrh, Jam't Batnh, Aljza'r, (2008). 